\title{
Four new species of Pilargidae (Annelida: Pilarginae) from the Gulf of Thailand
}

\author{
JINTANA PLATHONG ${ }^{1,2}$, HARLAN K. DEAN ${ }^{3} \&$ SAKANAN PLATHONG ${ }^{2 *}$ \\ ${ }^{1}$ Marine Ecosearch Management Co., Ltd., 4/31 Moo 1, Namnoi, Hat Yai, Songkhla 90110, Thailand. \\ ”klaklong@hotmail.com; @ https://orcid.org/0000-0002-2136-3770 \\ ${ }^{2}$ Marine Science Learning Center, Faculty of Science, Prince of Songkla University, Hat Yai, Songkhla 90110 Thailand. \\ "="sakanan2004@yahoo.com; 이ttps://orcid.org/0000-0003-3473-1680 \\ ${ }^{3}$ Museum of Comparative Zoology, Department of Invertebrate Zoology, 26 Oxford St. Cambridge, MA 02138, USA. \\ ”"harlan.dean@umb.edu; ○ https://orcid.org/0000-0001-8269-0671 \\ ${ }^{*}$ Corresponding author
}

\begin{abstract}
Four new species belonging to the Family Pilargidae, Ancistrosyllis kornkanokae sp. nov., A. nakkaritae sp. nov., Cabira saithipae sp. nov., and $C$. thailandica sp. nov. were collected from 9-27 m depth in soft sediments in the Songkhla Sea, Gulf of Thailand. Ancistrosyllis kornkanokae sp. nov. can be distinguished from other species in the genus by the presence of a small median antenna on the prostomium; two pairs of elongate tentacular cirri; and short limbate neurochaetae with unidentate curved pointed tips. Ancistrosyllis nakkaritae sp. nov. is characterized by having a conspicuous median antenna and elongate lateral antennae longer than palps; and short limbate neurochaetae with bifid tips. While Cabira saithipae sp. nov. is characterized by the presence of the first notopodial hook at chaetiger eight, large, conical papillae ont chaetigers 7-17 and the presence of both short, recurved tipped and short, curved tip chaetae in anterior chaetigers. Cabira thailandica sp. nov. is distinguished from other species in the genus by the first notopodial hooks occurring at chaetiger seven and the presence of long, non-limbate capillary neurochaetae with bidentate tips. Updated keys to the genera Ancistrosyllis and Cabira are also provided.
\end{abstract}

Key words: Ancistrosyllis, Cabira, pilargids, Songkhla Sea, taxonomy

\section{Introduction}

Members of the Pilargidae are distributed worldwide in marine and estuarine soft sediments (Glasby 2000) and are a well-represented family in both the Andaman Sea and the Gulf of Thailand but they have been little studied. Only two species of this family have been described from Thailand. Hermundura annandalei (Fauvel 1932) was described from Songkhla Lake (or Songkhla Lagoon), a blackish water system in Songkhla Province, in southern Thailand (Fauvel 1932; Salazar-Vallejo et al. 2001). The second species, Sigambra phuketensis Licher \& Westheide, 1997 was described from Phuket Island in the Andaman Sea (Licher \& Westheide 1997). There have been no other records of the family from this region.

In the present study samples were collected during two large projects in the Songkhla Sea, Gulf of Thailand and were sorted and material of the family Pilargidae separated. The first project "Environmental Monitoring Projects in the Petroleum Production Area in Songkhla Sea", undertaken between 2011-2019, was intended to assess benthic diversity at several stations among oil production areas of Songkhla Sea, Thailand. The second project "Marine and Coastal Resources Databases and Marine Community under Petroleum Platform in Songkhla Province" aimed to explore the seasonal variation of marine benthic fauna from the southern province of Songkhla, undertaken between 2012-2016.

In this paper, we describe two new species of Ancistrosyllis and two new species of Cabira from the Songkhla Sea, Gulf of Thailand, with figures and keys provided. Further papers will deal with other species and other genera belonging to the Pilargidae.

There have been 13 previously described species of Ancistrosyllis (Read \& Fauchald 2021a) and here we 
describe two new species. We can separate species of Ancistrosyllis into three groups based on the characteristics of the antennae (Table 1). The first group (Group I) consists of a single species, A. quellina Wesenberg-Lund, 1962, with only a median antenna. In the second group (Group II) both a median antenna and two lateral antennae are present. This group now includes nine species: A. breviceps Hartman, 1963; A. cingulata Korschelt, 1893; A. commensalis Gardiner, 1976; A. fioronii Fiege \& Böggemann, 1999; A. groenlandica McIntosh, 1878; A. hartmanae Pettibone, 1966; A. jonesi Pettibone, 1966; and two new species from this study, A. kornkanokae sp. nov. and A. nakkaritae sp. nov. Among these species only two; $A$. cingulata and $A$. hartmanae have a pair of eyespots on the prostomium. The last group (Group III) has only a pair of lateral antennae but no median antenna. This group includes five species: $A$. carolinensis Gardiner, 1976; A. falcata Day, 1957; A. hamata Hartman, 1960; A. matlaensis Mandal \& Deb, 2018; and A. papillosa Jones, 1961 (Table 1).

The genus Cabira Webster, 1879, consists of 5 valid species; C. bohajensis Britaev \& Saphronova, 1981 from Japan; C. brevicirris Rangarajan, 1964 from India; C. incerta Webster, 1879 from the Gulf of Mexico; $C$. pilargiformis Uschakov \& Wu, 1962 from the Yellow Sea, China; and C. rangarajani Mandal, Harkantra \& SalazarVallejo, 2007 from India (Read \& Fauchald 2021b). This study adds two new species, C. saithipae sp. nov. and $C$. thailandica sp. nov., to the genus Cabira.

\section{Materials and methods}

Specimens were collected from 2011 to 2019 in the Songkhla sea, the southern Gulf of Thailand (7¹4'21"$7^{\circ} 49^{\prime} 22^{\prime \prime} \mathrm{N}, 100^{\circ} 24^{\prime} 42^{\prime \prime}-100^{\circ} 49^{\prime} 01^{\prime \prime} \mathrm{E}$ (Fig. 1), with a Van Veen grab $\left(0.1 \mathrm{~m}^{2}\right)$ at depths ranging from 10 to $27 \mathrm{~m}$ by the Marine Ecosearch Management Company. The samples were sieved with $2.0 \mathrm{~mm}, 1.0 \mathrm{~mm}$ and $0.5 \mathrm{~mm}$ mesh stacked screens in the field. Water and sediment from the grab samples were passed through a $300 \mu \mathrm{m}$ filter bag. The material retained by both methods was fixed with $4 \%$ formaldehyde in a seawater solution. In the laboratory the samples were washed with freshwater and transferred to $70 \%$ ethanol. Polychaetes were sorted into taxonomic groups using a stereomicroscope and those belonging to the new species were examined under dissecting and compound light microscopes. Light photographs and measurements of the specimens were produced using a stereo microscope (Olympus SZX16) with a digital camera (DP74) and a compound microscope (Leica DM 1000) with a digital camera (DP74). Stacks of multifocal shots were merged into a single photograph using the Helicon Focus program. Specimens were temporally stained with Shirlastain-A for observing the median antenna and papillae on the body.

Specimens of new species were examined using the Scanning Electron Microscopy (SEM). They were dehydrated in $100 \%$ ethanol before being critical point dried and mounted onto SEM stubs and then coated with gold. SEM photographs were taken with a Field Emission Scanning Electron Microscope (Apreo, FEI).

Confirmation of the taxonomic status of the new species was based on the revision and compilation of the diagnostic characteristics from all recognized species of the genus Ancistrosyllis and Cabira done by Glasby \& Salazar-Vallejo (2021); Mandal \& Deb (2018); Mandal et al. (2007); Fiege \& Böggemann (1999); Pettibone (1966) and Rangarajan (1964). For comparative purposes tables with the main diagnostic characters of the new species and closely-related species were prepared (Tables 1-2).

Type specimens are deposited in the Princess Maha Chakri Sirindhorn Natural History Museum, Prince of Songkla University (PSUZC), Thailand and Australian Museum (AM), Sydney, Australia. Additional non-type specimens are maintained in the personal collections of JP \& SP at MEM (Marine Ecosearch Management Co., Ltd.).

\section{Results}

\section{Systematics}

Family Pilargidae Saint-Joseph, 1899

Subfamily Pilarginae Saint-Joseph, 1899 


\section{Genus Ancistrosyllis McIntosh, 1878}

Diagnosis (after Glasby \& Salazar-Vallejo 2021). Pilargids with body depressed, integument papillose to verrucose, present on both segmental and nonsegmental regions. Antennae, 0-3. Palps unfused, biarticulated; palpostyle minute. Paired ventrolateral palpal papillae present. Pharynx distally with terminal papillae (or absent); proximally smooth or, rarely, with denticles. Two pairs of tentacular cirri. Dorsal and ventral cirri digitate to lobate. Notochaetae are hooks, present from chaetigers 3 to 13 and continuing throughout body. Neurochaetae smooth, or spinulose capillaries, often with bidentate tips. Free living in sediments from intertidal to deep sea, or commensal with other invertebrates.

\section{Key to the species of Ancistrosyllis McIntosh, 1878}

1A Prostomium with only a median antenna with two pairs of eyespots and one pair of small, subulate tentacular cirri. ..... Chile, SE Pacific

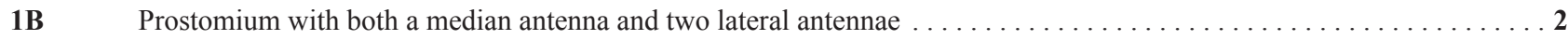

1C Prostomium with two lateral antennae, median antenna absent $\ldots \ldots \ldots \ldots \ldots \ldots \ldots \ldots \ldots \ldots \ldots \ldots \ldots$

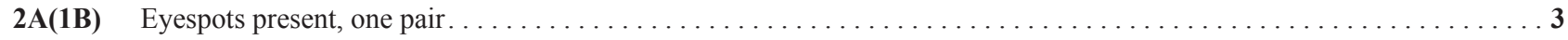

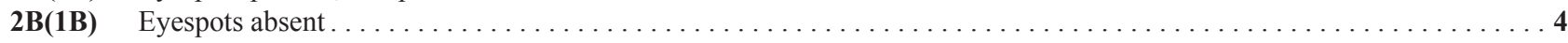

3A(2A) Two pairs of short, subequal tentacular cirri; dorsal cirri from chaetiger 1 and ventral cirri from chaetiger 3; first notopodial hooks from chaetiger 3 . A. hartmanae Pettibone, 1966; Chesapeake Bay to Gulf of Mexico, Western Atlantic

3B(2A) Two pairs of tentacular cirri, both dorsal and ventral cirri from chaetiger 1; first notopodial hooks from chaetiger $5 \ldots . .$.

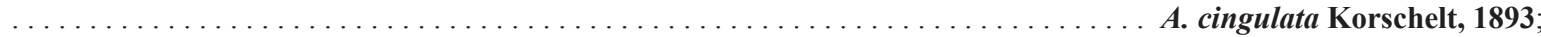
Adriatic Sea

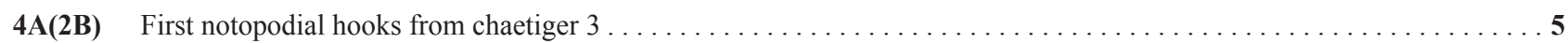

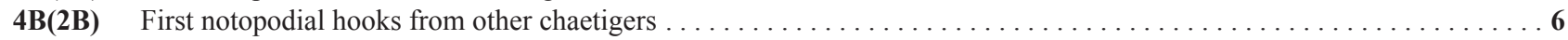

5A(4A) Dorsal and ventral cirri from chaetiger 1; neurochaetae 2 types, bifid tips . . . . . . . . . A. nakkaritae sp. nov.; Gulf of Thailand, Western Pacific

5B(4A) Dorsal cirri from chaetiger 1; ventral cirri from chaetiger $2 \ldots \ldots \ldots \ldots \ldots \ldots$ A. fioronii Fiege \& Böggemann, 1999; North Sea, Atlantic Ocean

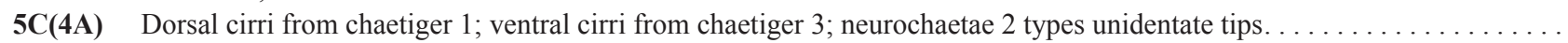
Gulf of Thailand, Western Pacific

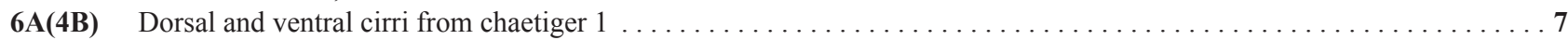

6B(4B) Dorsal cirri from chaetiger 1 ; ventral cirri from chaetiger 3 , first notopodial hooks from chaetiger $6 \ldots \ldots \ldots \ldots \ldots$

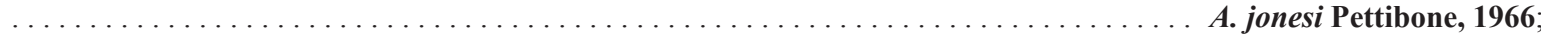
Maryland, Atlantic Ocean

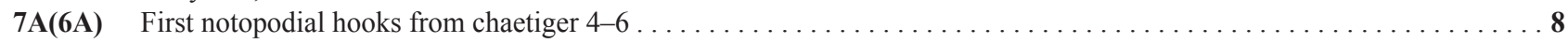

7B(6A) First notopodial hooks from chaetiger $13 \ldots \ldots \ldots \ldots \ldots \ldots \ldots \ldots \ldots \ldots \ldots \ldots$ breviceps Hartman, 1963; Southern California, Pacific Ocean

8A(7A) First dorsal cirri twice as long as following ones $\ldots \ldots \ldots \ldots \ldots \ldots \ldots \ldots \ldots$. groenlandica McIntosh, 1878; off Greenland, Arctic Ocean

8B(7A) First notopodial hooks from chaetiger $6 \ldots \ldots \ldots \ldots \ldots \ldots \ldots \ldots \ldots \ldots \ldots$. commensalis Gardiner, 1976; North Carolina, Atlantic Ocean

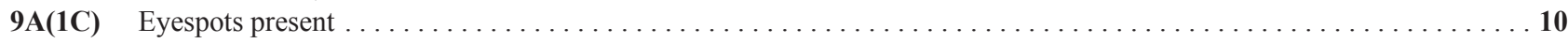

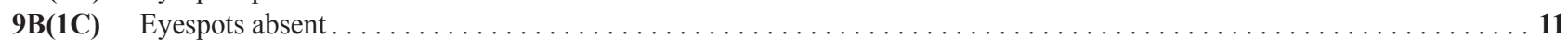

10A(9A) First notopodial hooks from chaetiger $3 \ldots \ldots \ldots \ldots \ldots \ldots \ldots \ldots \ldots \ldots \ldots \ldots \ldots$. papillosa Jones, 1961; USA coast of Gulf of Mexico

10B(9A) First notopodial hooks from chaetiger $7 \ldots \ldots \ldots \ldots \ldots \ldots \ldots \ldots \ldots \ldots \ldots \ldots \ldots \ldots \ldots \ldots \ldots$ falcata Day, 1957; South Africa

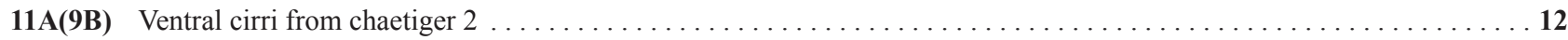

11B(9B) Ventral cirri from chaetiger 3; notopodial hooks from chaetigers $4-7 \ldots \ldots \ldots \ldots \ldots \ldots$. hamata Hartman, 1960; Southern California, Pacific Ocean

12A(11A) Notopodial hooks from chaetiger $6 \ldots \ldots \ldots \ldots \ldots \ldots \ldots \ldots \ldots \ldots \ldots \ldots \ldots \ldots \ldots$. carolinensis Gardiner, 1976; North Carolina to the Gulf of Mexico, Western Atlantic

12B(11A) Notopodial hooks from chaetiger 7 . Estuarine System, India, Indian Ocean 


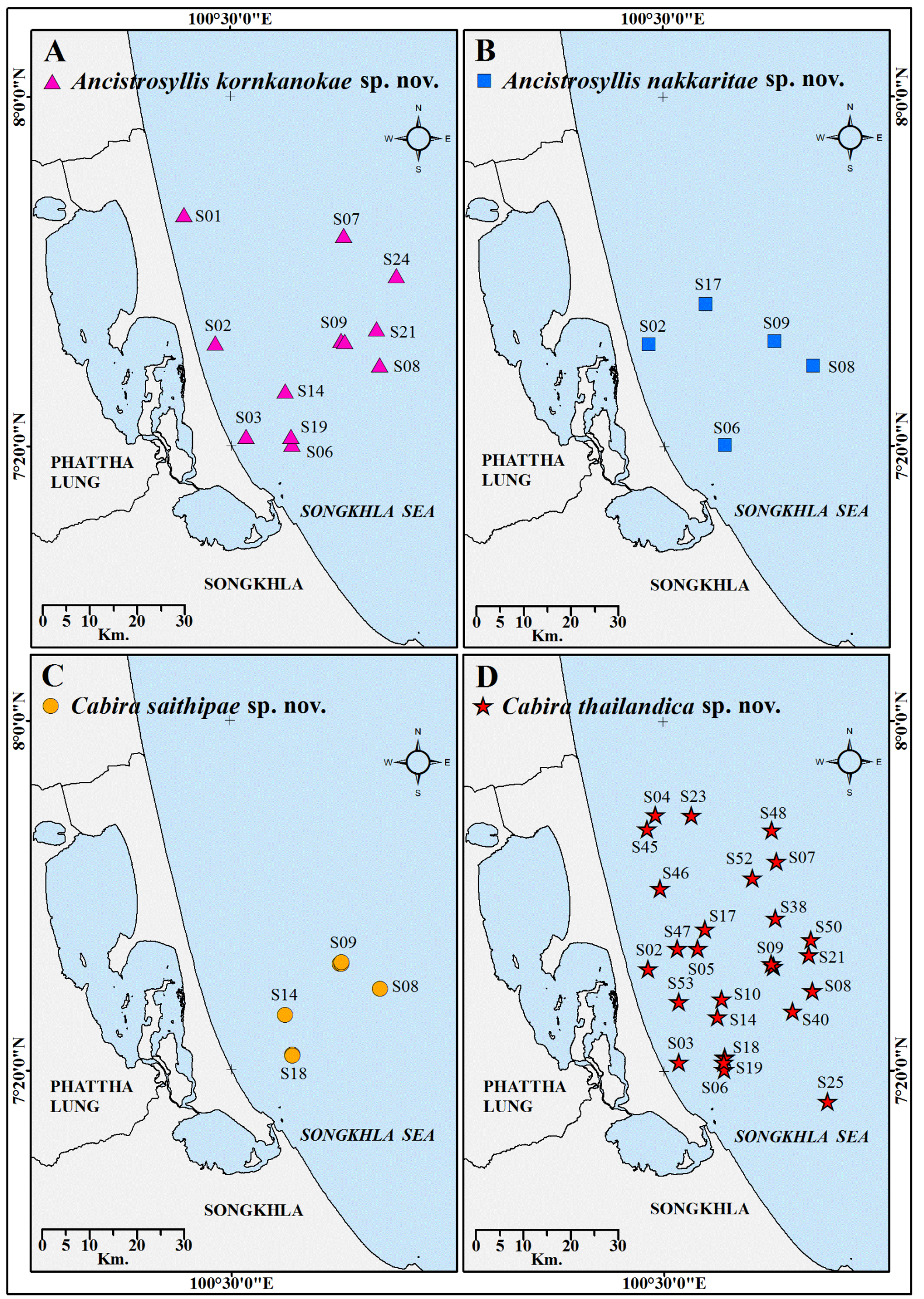

FIGURE 1. Sampling sites in the Songkhla Sea, Gulf of Thailand, showing stations where new species of Ancistrosyllis and Carbira specimens were collected. A. Ancistrosyllis kornkanokae sp. nov. (triangles); B. Ancistrosyllis nakkaritae sp. nov. (squares); C. Cabira saithipae sp. nov. (circles); D. Cabira thailandica sp. nov. (stars). 


\section{Ancistrosyllis kornkanokae sp. nov.}

Figs $2-4$

Material examined. Twenty one specimens, collected from the Songkhla Sea, Gulf of Thailand, Western Pacific. Coll. MEM (Marine Ecosearch Management Co., Ltd.), mud mixed with sand and shells. Holotype: PSUZC-POL0187 (1 spec.), S02 (7³1'44”N, 100²8'15”E), 15 Mar 2016, 10.0 m. Paratypes: PSUZC-POL-0188 (1 spec.),

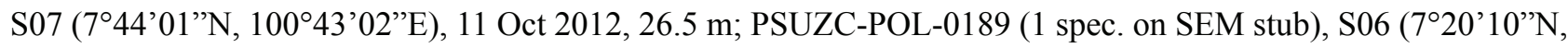
100³6'59”E), 20 Feb 2013, 15.5 m; PSUZC-POL-0190 (1 spec.), S09-17 (7³1'55”N, 10043’06”E), 16 Mar

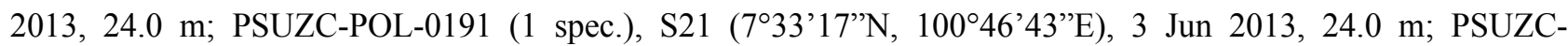
POL-0192 (1 spec.), S24 (7³9’22”N, 10049’01”E), 30 Oct 2014, 27.0 m; PSUZC-POL-0193 (1 spec.), S01

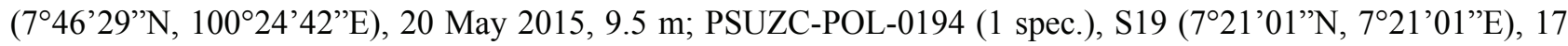
Jul 2015, 14.0 m; PSUZC-POL-0195 (3 specs., 1 spec. on SEM stub), S08 (7²9’10”N, 10047’06”E), 16 Mar 2016, 25.0 m; PSUZC-POL-0196 (1 spec. on SEM stub), S09-3 (7³2' '’”N, 10042’41”'E), 16 Aug 2018, 24.0 m; PSUZC-POL-0197 (1 spec.), S08 (7²9’10”N, 10047’06”E), 5 May 2016, 25.0 m; PSUZC-POL-0198 (1 spec.), S03 (7²1’02”N, 100³1'45”E), 18 Oct 2016, 9.0 m; PSUZC-POL-0199 (3 specs., 1 spec. on SEM stub), S14 (7'26'14’'N, 100³6'13”'E), 18 Aug 2018, $15.5 \mathrm{~m}$.

Additional Material. 2 specs., S07 ( $\left.7^{\circ} 44^{\prime} 01^{\prime \prime N}, 100^{\circ} 43^{\prime} 02^{\prime \prime E}\right), 18$ May 2016, 26.5 m; 2 specs., S09-10 (7³1'56”'N, 10042’47’E), 17 Mar 2013, $24.3 \mathrm{~m}$.

Type locality. Songkhla Sea, Gulf of Thailand (Fig. 1A).

Diagnosis. Ancistrosyllis lacking eyespots; median and lateral antennae present; tentacular cirri elongate. Dorsal cirri from chaetiger 1; ventral cirri from chaetiger 3. Notopodial hooks from chaetiger 3; neurochaetae with 2-3 short limbate chaetae per bundle, each with curved pointed tips and non-limbate capillary chaetae.

Description. Holotype complete, $14.2 \mathrm{~mm}$ long and $0.45 \mathrm{~mm}$ wide for 66 chaetigers. Body whitish, transparent with eggs within body cavity. Paratypes incomplete, depressed, tapered anteriorly, 1.1-6.7 mm long, 0.26-0.50 $\mathrm{mm}$ wide with 9-34 chaetigers. Prostomium bilobed, short, broad, papillose, wider than long (163 $\mu \mathrm{m}$ length and $355 \mu \mathrm{m}$ wide); lateral antennae shorter than palps (Figs 2A, B, D, 3A). Posterior prostomial margin with minute papilla like median antenna ( $23 \mu \mathrm{m}$ length and $26 \mu \mathrm{m}$ wide) (Figs 2B-D, 4A). Eyespots absent, palps with small ventrolateral palpal papillae (Figs 2A, D, 3A). Proboscis retracted in holotype, visible in SEM specimen.

Peristomium short; tentacular cirri two pairs, elongate, papillose, subequal, dorsal tentacular cirri slightly longer than ventrals (Figs 2A-B, D, 4A).

Parapodia sub-biramous with reduced notopodial lobe; neuropodia truncate, straight. Dorsal cirri from first chaetiger, long, slender, papillose, longer than tentacular cirri; first dorsal cirri 3.8 times length of that of chaetiger 2; dorsal cirri increase in length from chaetiger 3 to about chaetiger 10 then decrease in length to posterior region. Ventral cirri from chaetiger 3 , shorter than dorsal cirri.

Notopodia each with single aciculum; large, strongly curved notopodial hooks (Figs 2D, 3A-C, 4B) from chaetiger 3 (Figs 2A, 2D, 4B) with 1-2 hooks per parapodium to the end of body. Neurochaetal bundles with 2-3 short limbate chaetae with curved pointed tips (unidentate) and up to six long, narrow, finely non-limbate capillary chaetae (Figs 3A, B, D-F, 4). Pygidium with two short, digitate, papillose anal cirri.

Etymology. The new species name is in honor of Miss Kornkanok Charoenmas of the Marine Ecosearch Management Company who has worked on the data base and distribution maps of the benthos in Thailand for more than 10 years.

Habitat. Found in 9-27 m depth, in mud mixed with sand and shells.

Distribution. Songkhla Sea, Gulf of Thailand, Western Pacific.

Remarks. Ancistrosyllis kornkanokae sp.nov. belongs to the second group of species in the genus Ancistrosyllis characterized by the presence of both a median antenna and two lateral antennae and the absence of eyespots (Table 1). Further, A. kornkanokae sp. nov. also has elongate, digitate, papillose tentacular cirri which differentiates this species from the other species in this group. Dorsal cirri are from chaetiger 1, longer than those present along subsequent chaetigers. Ventral cirri short, conical, papillose from chaetiger 3. It resembles A. fioronii Fiege \& Böggemann, 1999 from North Sea, Atlantic Ocean; A. hartmanae Pettibone, 1966 from Chesapeake Bay, USA; and A. nakkaritae sp. nov. in group two by having a median antenna, two lateral antennae, and first notopodial hooks begin at chaetiger 3 .

However, A. kornkanokae sp. nov. differs from A. fioronii and A. nakkaritae sp. nov. because they all have the 
first ventral cirri from different chaetigers. The first ventral cirri are present at chaetiger 3 in $A$. kornkanokae but in $A$. fioronii and $A$. nakkaritae sp. nov., first ventral cirri start from chaetiger 2 and chaetiger 1, respectively. Moreover, tentacular cirri in A. kornkanokae are longer than A. fioronii (in A. fioronii has short tentacular). A. kornkanokae sp. nov. also differs from $A$. fioronii by have two types of neurochaetae as short limbate chaeta and long nonlimbate chaeta with unidentate tips. Whereas $A$. fioronii has only one type of non-limbate capillary neurochaeta with bidentate tip (Fiege \& Böggemann 1999).

Ancistrosyllis kornkanokae sp. nov. differs from A. nakkaritae sp. nov. in that all neurochaetae are unidentate but in $A$. nakkaritae sp. nov., all neurochaetae have bifid tips.

Ancistrosyllis kornkanokae sp. nov. mostly resembles A. hartmanae Pettibone, 1966 in having the first dorsal and ventral cirri occurring on similar chaetigers (chaetiger 1 and chaetiger 3, respectively) and first hooks occur from chaetiger 3 (Pettibone 1966). However, in A. hartmanae eyespots are present and the tentacular cirri are short, while in A. kornkanokae sp. nov. eyespots are absent and the tentacular cirri are longer (Table 1).
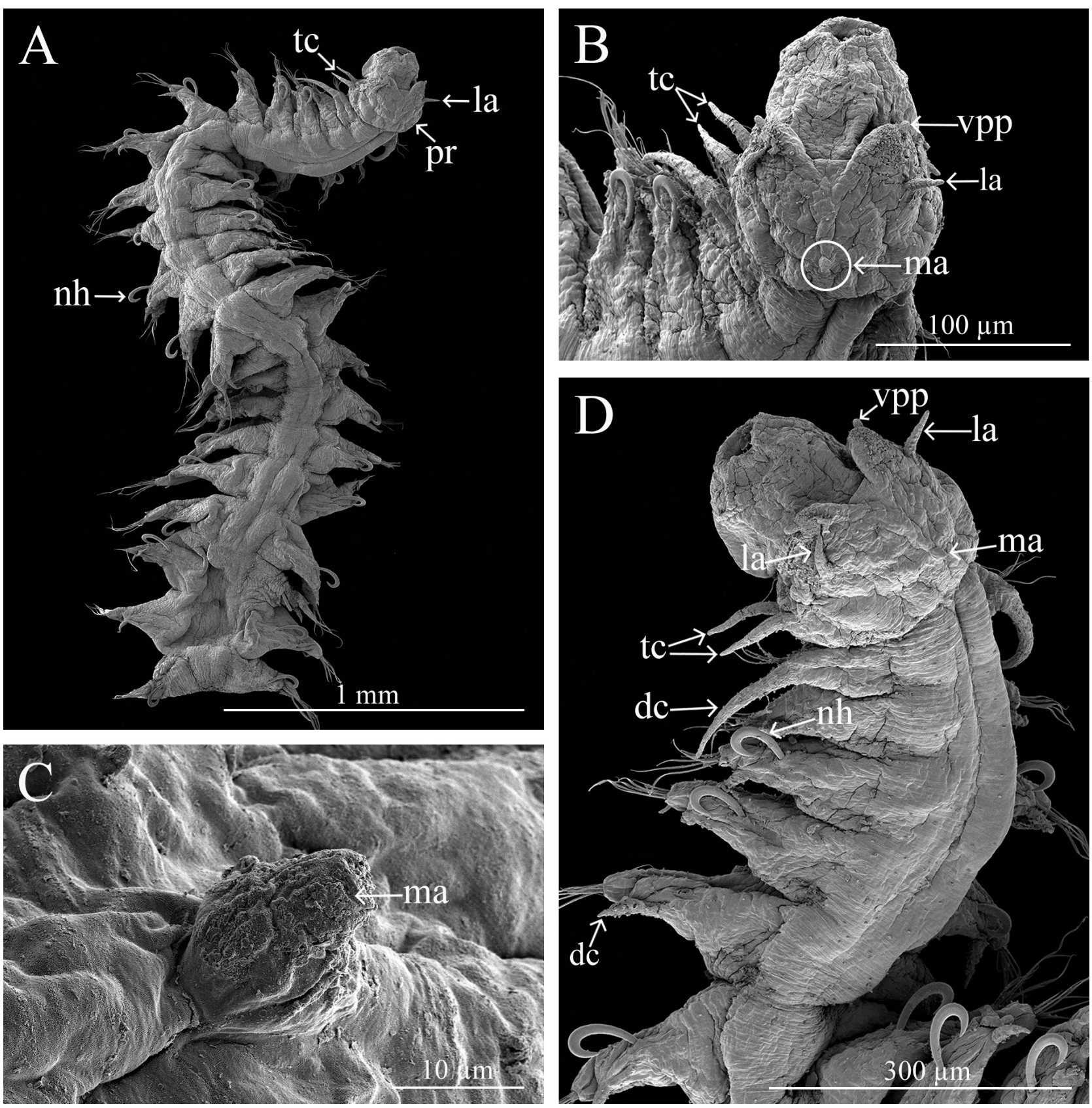

FIGURE 2. Scanning electron micrographs of Ancistrosyllis kornkanokae sp. nov. (PSUZC-POL-0189) show A. Anterior region, dorsal view; B. Prostomium, dorsal view; C. Median antenna, lateral view; D. Anterior end, lateral view. Abbreviations: dc: dorsal cirri, la: lateral antenna, ma: median antenna, nh: notopodial hook, pr: prostomium, tc: tentacular cirri, vpp: ventrolateral palpal papilla. 

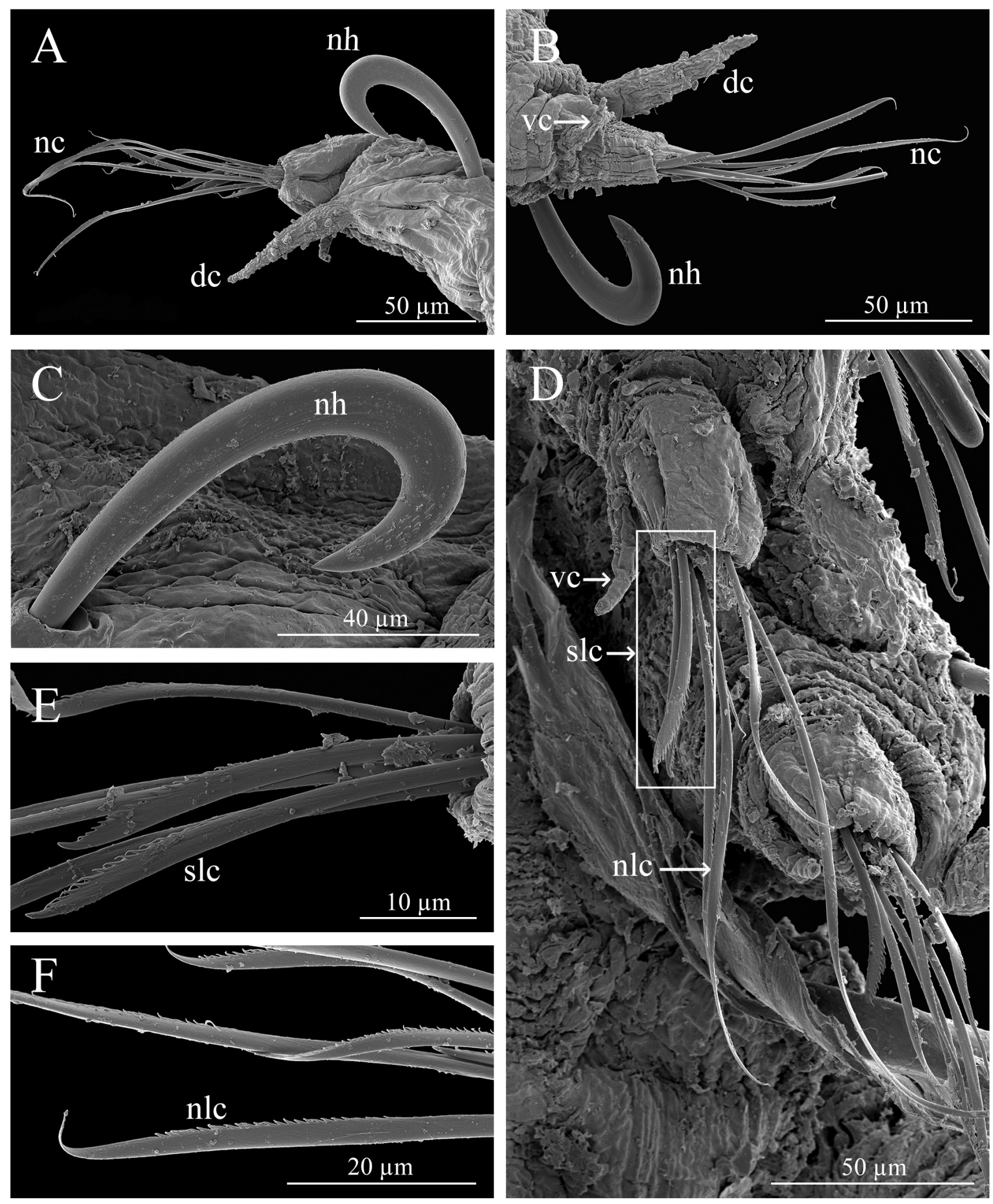

FIGURE 3. Scanning electron micrographs of Ancistrosyllis kornkanokae sp. nov. (A-C, PSUZC-POL-0189; D-F, PSUZCPOL-0196) show A. Anterior parapodia, dorsal view; B. Anterior parapodia, ventral view; C. Notopodial hook, lateral view; D. Neurochaetae, in the box shows Short limbate chaeta, lateral view; E. Close up short limbate chaeta with unidentate tip, lateral view; F. Tip of long capillary non limbate chaetae with unidentate tip. Abbreviations: dc: dorsal cirri, nlc: non-limbate capillary chaeta, nc: neurochaetae, nh: notopodial hook, slc: short limbate chaetae, vc: ventral cirri. 
A

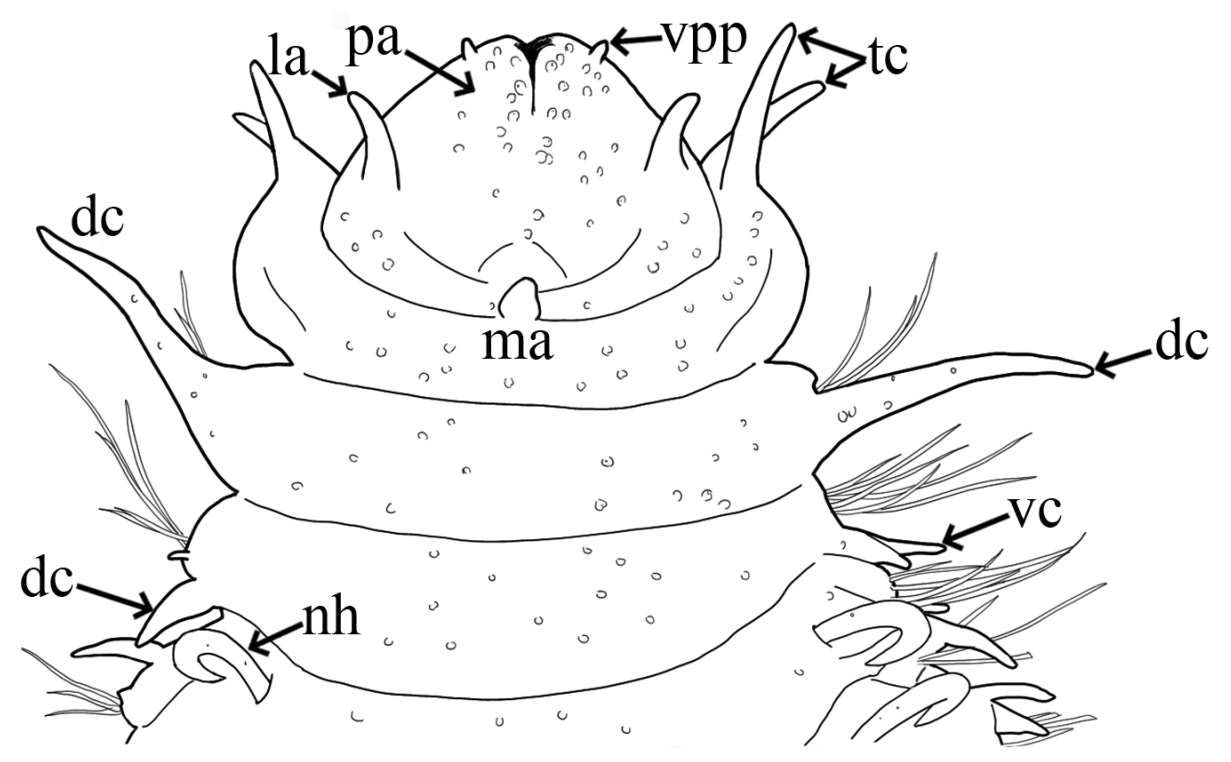

$100 \mu \mathrm{m}$
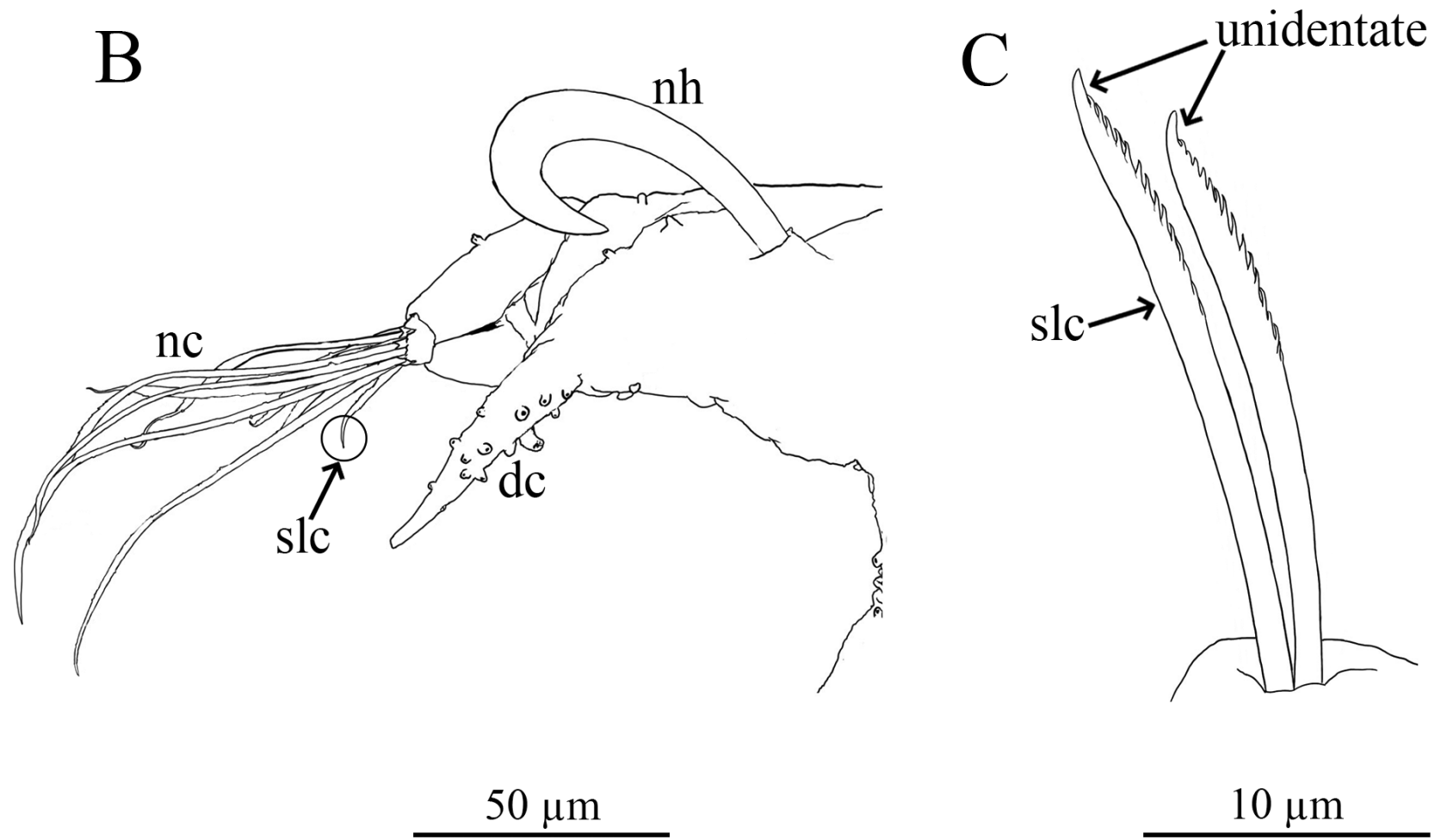

FIGURE 4. Line drawings of Ancistrosyllis kornkanokae sp. nov. illustrate A. Anterior end, dorsal view; B. Neurochaetae, lateral view; C. Close up short limbate chaetae with unidentate tips. Abbreviations: dc: dorsal cirri, la: lateral antenna, ma: median antenna, nc: neurochaetae, nh: notopodial hook, pa: palp, slc: short limbate chaeta, tc: tentacular cirri, vc: ventral cirri, vpp: ventrolateral palpal papilla. 


\section{Ancistrosyllis nakkaritae sp. nov.}

Figs 5-8

Material examined. Five specimens, collected from the Songkhla Sea, Gulf of Thailand, Western Pacific. Coll. MEM (Marine Ecosearch Management Co., Ltd.), mud mixed with sand and shells. Holotype: PSUZC-POL0310 (1 spec.), S06 (7²0'9”N, 100³6'58”E), 15 Mar 2016, 15.5 m. Paratypes: PSUZC-POL-0311 (1 spec., on

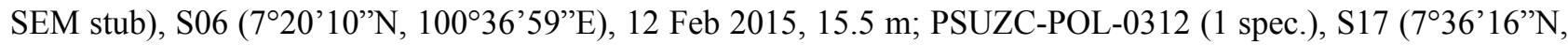

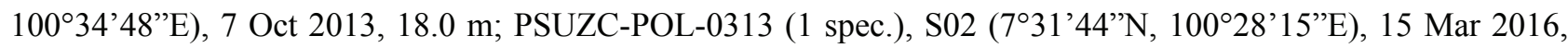
10.0 m; PSUZC-POL-0314 (1 spec.), S09-3 (7³2’1’N, 10042’41’E), 16 Aug 2018, 24.0 m.

Type locality. Songkhla Sea, Gulf of Thailand (Fig. 1B).

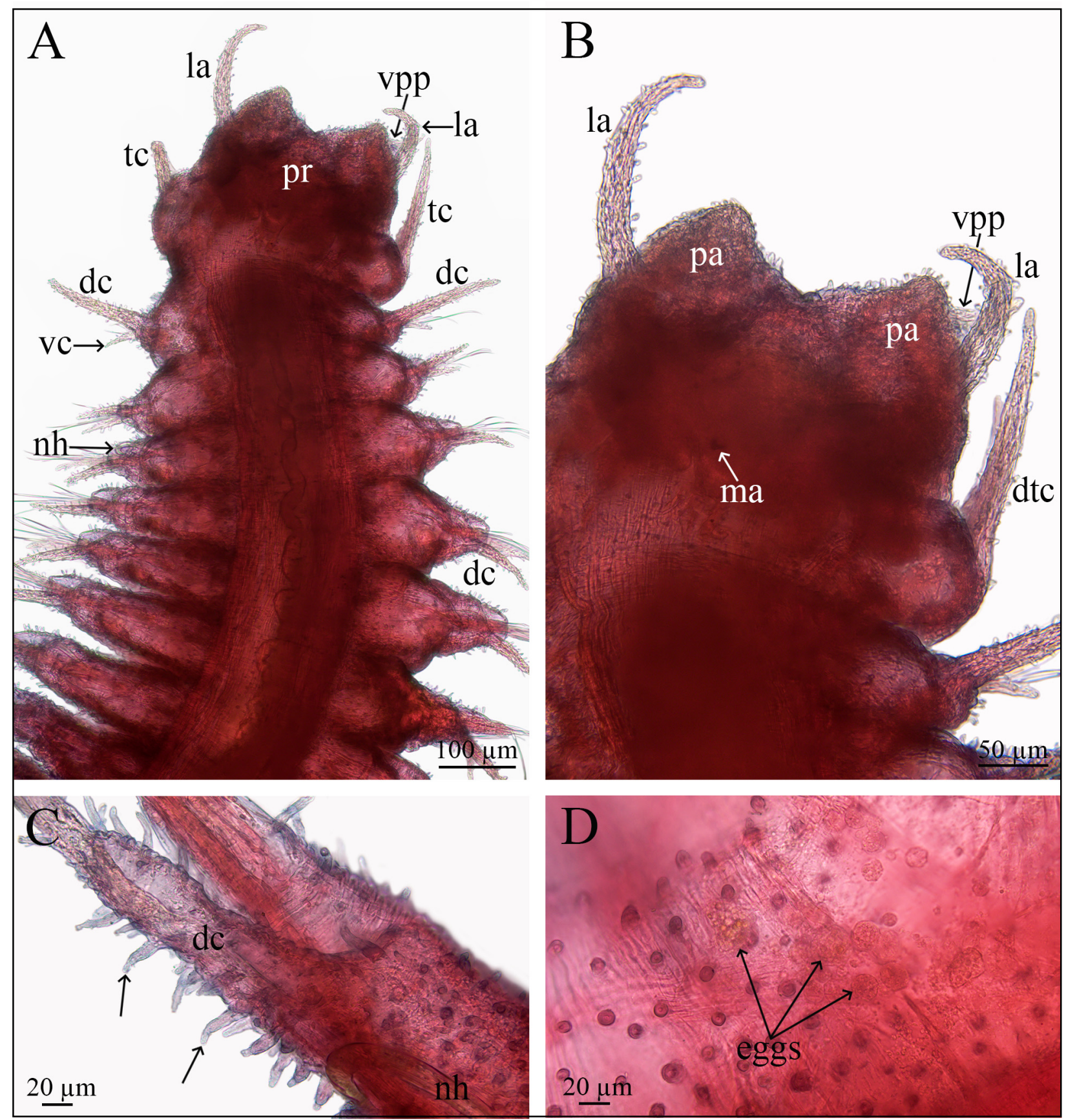

FIGURE 5. Light photographs of Ancistrosyllis nakkaritae sp. nov. stained with Shirlastain-A (Holotype, PSUZC-POL-0310) A. Anterior region, dorsal view; B. Close up prostomium, dorsal view; C. Close up long papillae at dorsal cirri, lateral view; D. Eggs in parapodia region, dorsal view. Abbreviations: dc: dorsal cirri, dtc: dorsal tentacular cirri, la: lateral antenna, ma: median antenna, nh: notopodial hook, pa: palp, pr: prostomium, tc: tentacular cirri, vc: ventral cirri, vpp: ventrolateral palpal papilla. 
Diagnosis. Ancistrosyllis nakkaritae sp. nov. is characterized by the absence of eyespots; the presence of a minute, conspicuous median antenna; elongate lateral antennae and tentacular cirri; and the first dorsal and ventral cirri start from chaetiger one. Dorsal and ventral tentacular cirri papillate, as long as lateral antennae, longer than first dorsal cirri. Notopodial hooks from chaetiger 3.

Description. Holotype incomplete, $8.7 \mathrm{~mm}$ long, $0.6 \mathrm{~mm}$ wide with 44 segments. Paratypes incomplete with 2.9-6.7 mm long, 0.3-0.7 mm wide and 21-40 segments. Body whitish, dorsal numerous of long papillae on the dorsal and ventral body throughout.

Prostomium broad, papillose, with two elongate papillose digitiform lateral antennae (162 and $130 \mu \mathrm{m}$ long), longer than the palps (Figs 5A-B, 6A-D, 8A). Median antenna very small, conspicuous present on the posterior of prostomium (Figs 5B, 6B, D, 8A). Eyespots absent, palps with small, digitate ventrolateral palpal papillae (Figs $5 \mathrm{~A}-\mathrm{B}, 6 \mathrm{C}-\mathrm{D}, 8 \mathrm{~A})$. Proboscis retracted in holotype and paratypes.
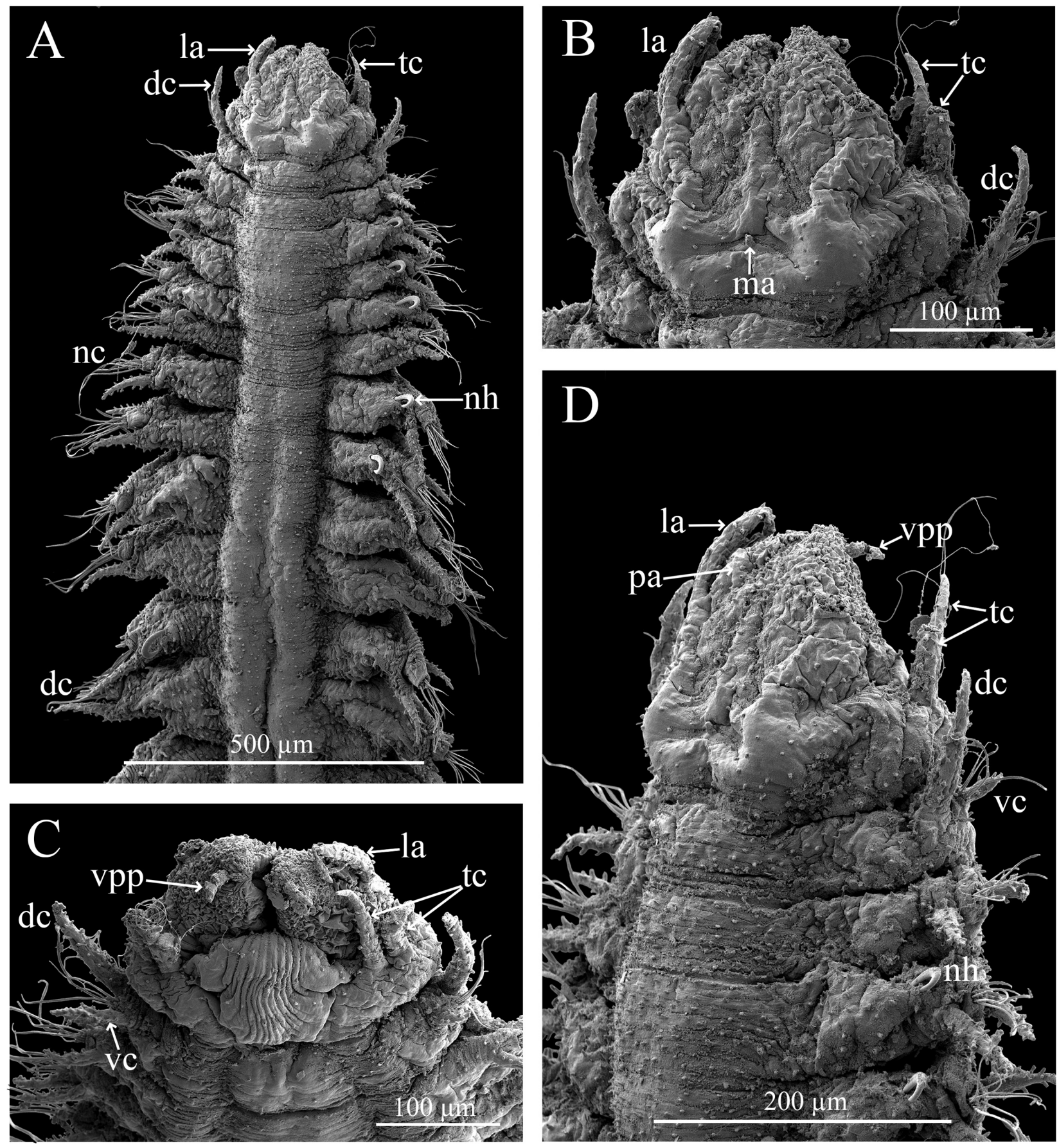

FIGURE 6. Scanning electron micrographs of Ancistrosyllis nakkaritae sp. nov. (PSUZC-POL-0311) show A. Anterior region, dorsal view; B. Anterior end, dorsal view; C. Same, lateral view. Abbreviations: dc: dorsal cirri, la: lateral antenna, ma: median antenna, nc: neurochaetae, nh: notopodial hook, tc: tentacular cirri, vc: ventral cirri, vpp: ventrolateral palpal papilla. 
Peristomium short with two pairs of elongate, digitate, papillose tentacular cirri (up to $203 \mu \mathrm{m}$ in complete dorsal tentacular cirri) inserted laterally, shorter than palps and longer than first dorsal cirri; dorsal tentacular cirri longer than ventral tentacular cirri and slightly longer than lateral antennae (Figs 5A-B, 6A-D, 8A).
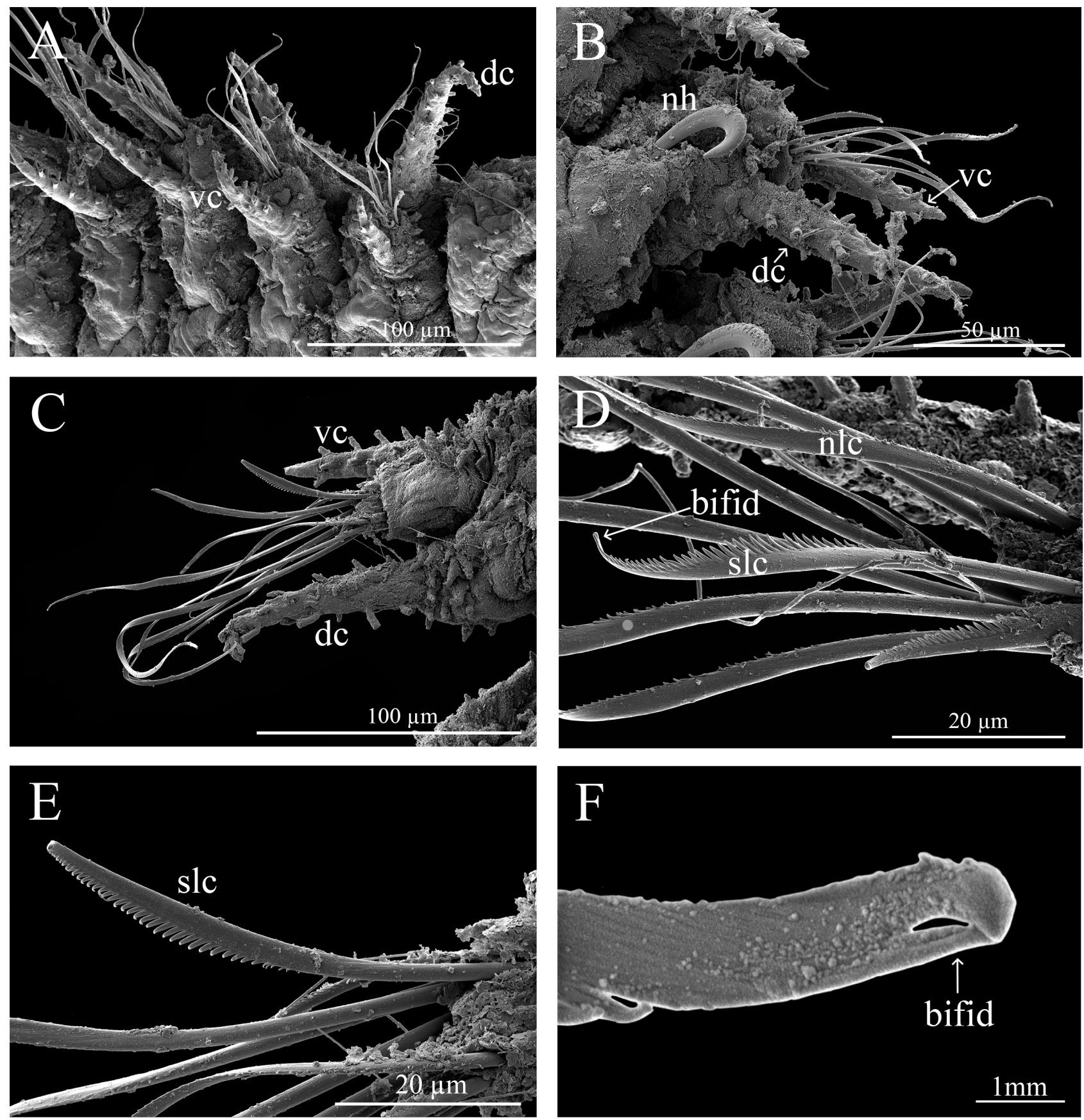

FIGURE 7. Scanning electron micrographs of Ancistrosyllis nakkaritae sp. nov. (PSUZC-POL-0311) show A. First four chaetigers, ventral view; B. Anterior parapodia, dorsal view; C. Anterior neurochaetae, ventral view; D. Same, close up short limbate chaetae with bifid tip, lateral view; E. Short limbate chaeta. Abbreviations: dc: dorsal cirri, nh: notopodial hook, nlc: non-limbate capillary chaeta, slc: short limbate chaeta, vc: ventral cirri.

Parapodia sub-biramous, with reduced notopodial lobe; neuropodia truncate and straight. Dorsal cirri long, conical, papillose with numerous large, elongate papillae; present from first chaetiger. First dorsal cirri long, about twice length of dorsal cirri at chaetiger 2. Subsequent several dorsal cirri shorter than those of chaetiger 1 but at chaetiger 3 dorsal cirri gradually increase in length until those of midbody being of greater length than those of chaetiger 1. Ventral cirri present from first chaetiger, shorter than dorsal cirri, longer than neuropodial lobes (Figs 5A, C, 6A-D, 7A-C, 8A, B). Notopodia each with single aciculum, chaetae absent. Large notopodial hooks present 
from chaetiger 3; strongly curved with one hook per parapodium (Figs 5A, 6A, D, 7B, 8A). Neurochaetal bundles with 2-4 short limbate chaetae with bifid tips and 5-8 long, narrow, finely toothed non-limbate chaetae with bifid tips (Figs 7A-D, 8B-C).

Pygidium unknown.

Reproduction. Holotype with eggs (collected in Mar 2016), (Fig. 7D).

Etymology. The new species is named in honor of Miss Nuenghathai Nakkarit, the marine biologist at MEM who has worked with us from the beginning of the Songkhla Sea project.

Habitat. Found at 10-24 m depth, mud mixed with sand and shells.

Distribution. Songkhla Sea, Gulf of Thailand, Western Pacific (Fig. 1B).

A

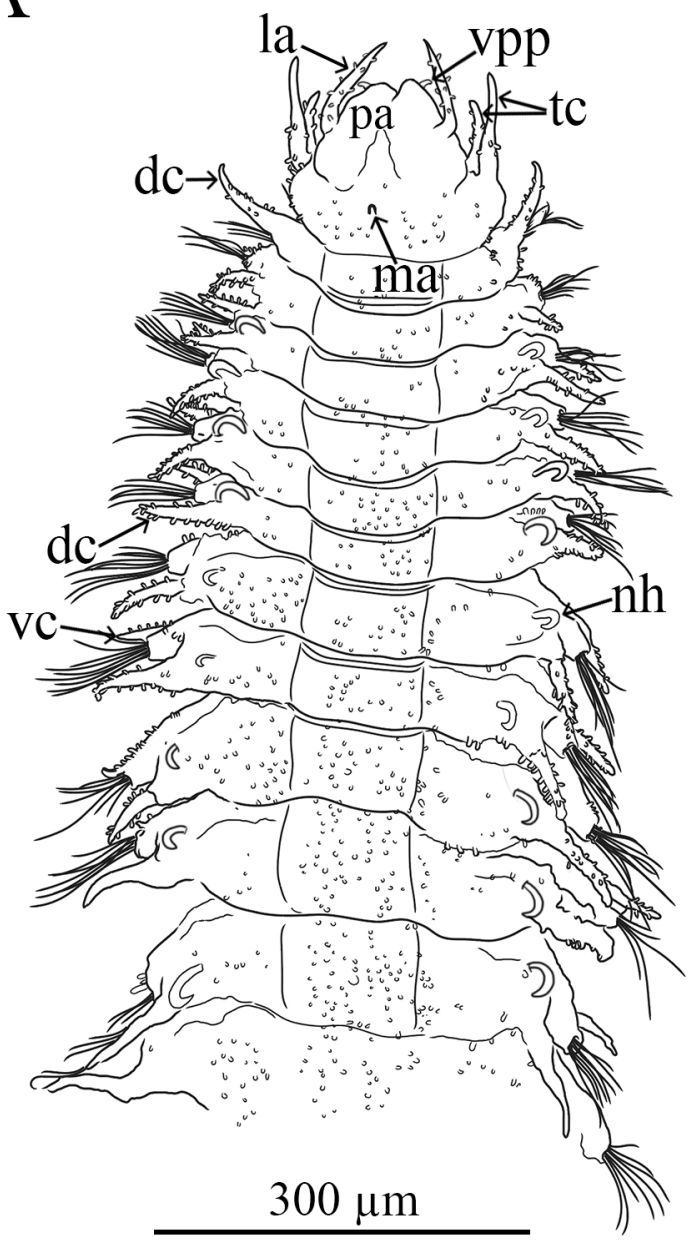

$\mathrm{B}$
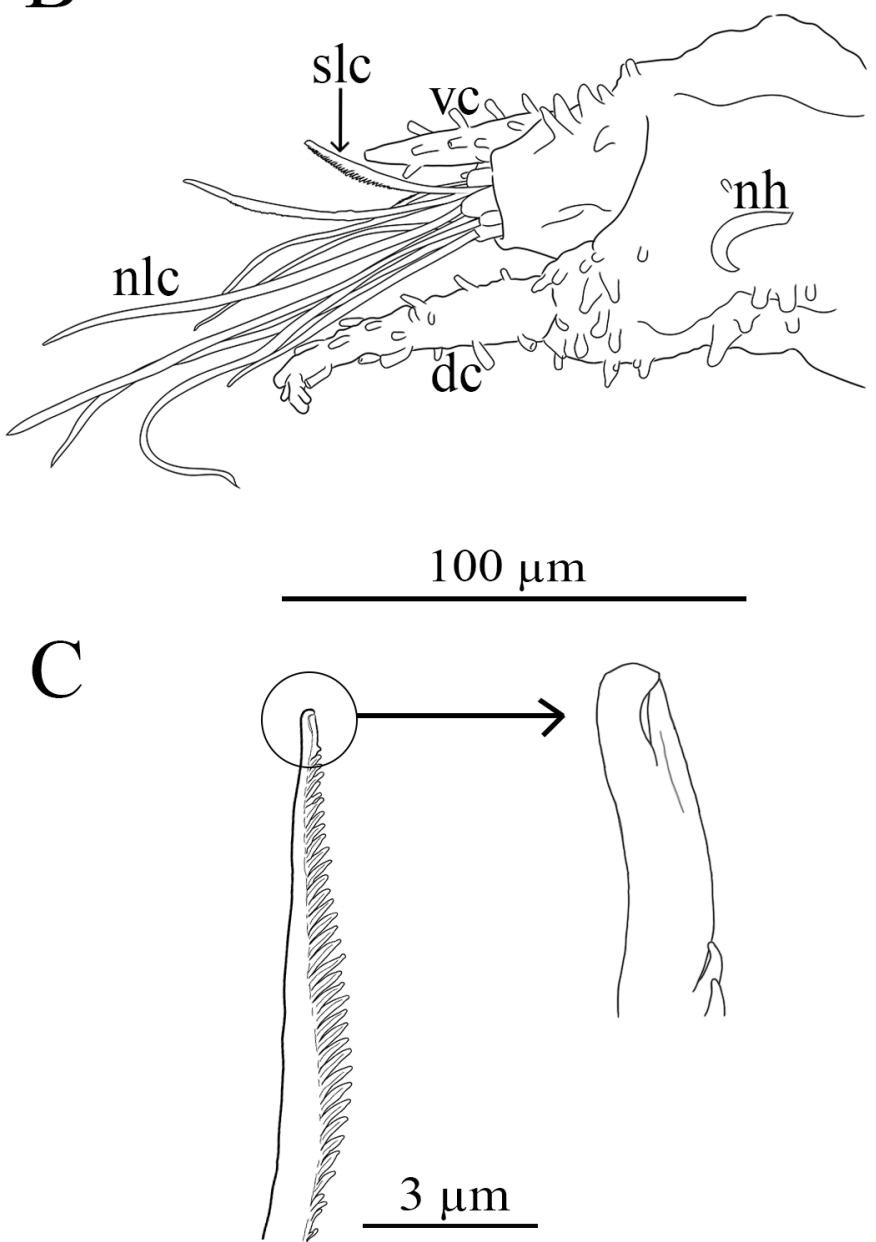

FIGURE 8. Line drawings of Ancistrosyllis nakkaritae sp. nov. illustrate A. Anterior region, dorsal view; B. Parapodia, lateral view; C. Close up Short limbate chaeta Abbreviations: dc: dorsal cirri, la: lateral antennae, ma: median antenna, nh: notopodial hook, nlc: non-limbate capillary chaeta, pa: palp, slc: short limbate chaeta, tc: tentacular cirri, vc: ventral cirri, vpp: ventrolateral palpal papilla.

Remarks. Ancistrosyllis nakkaritae sp. nov. belongs to the second group of species in the genus Ancistrosyllis characterized by the presence of both a median antenna and two lateral antennae. It mostly resembles $A$. fioronii Fiege \& Böggemann, 1999 and A. kornkanokae sp. nov. of this group by having the first dorsal cirri start from chaetiger 1, the absence of eyespots and first notopodial hooks begin at chaetiger 3 (Table 1).

Ancistrosyllis nakkaritae sp. nov. differs from A. fioronii and A. kornkanokae sp. nov. in having the first ventral cirri from chaetiger 1 instead chaetiger 2 as in A. fioronii (Fiege \& Böggemann 1999) and chaetiger 3 in $A$. kornkanokae sp. nov.. Moreover, the lateral antennae and tentacular cirri in A. nakkaritae sp. nov. are longer than those of $A$. fioronii and $A$. kornkanokae sp. nov., and the median antenna in A. nakkaritae sp. nov. is conspicuously smaller. A. nakkaritae sp. nov. also differs from A. fioronii by having two types of neurochaetae and a higher 


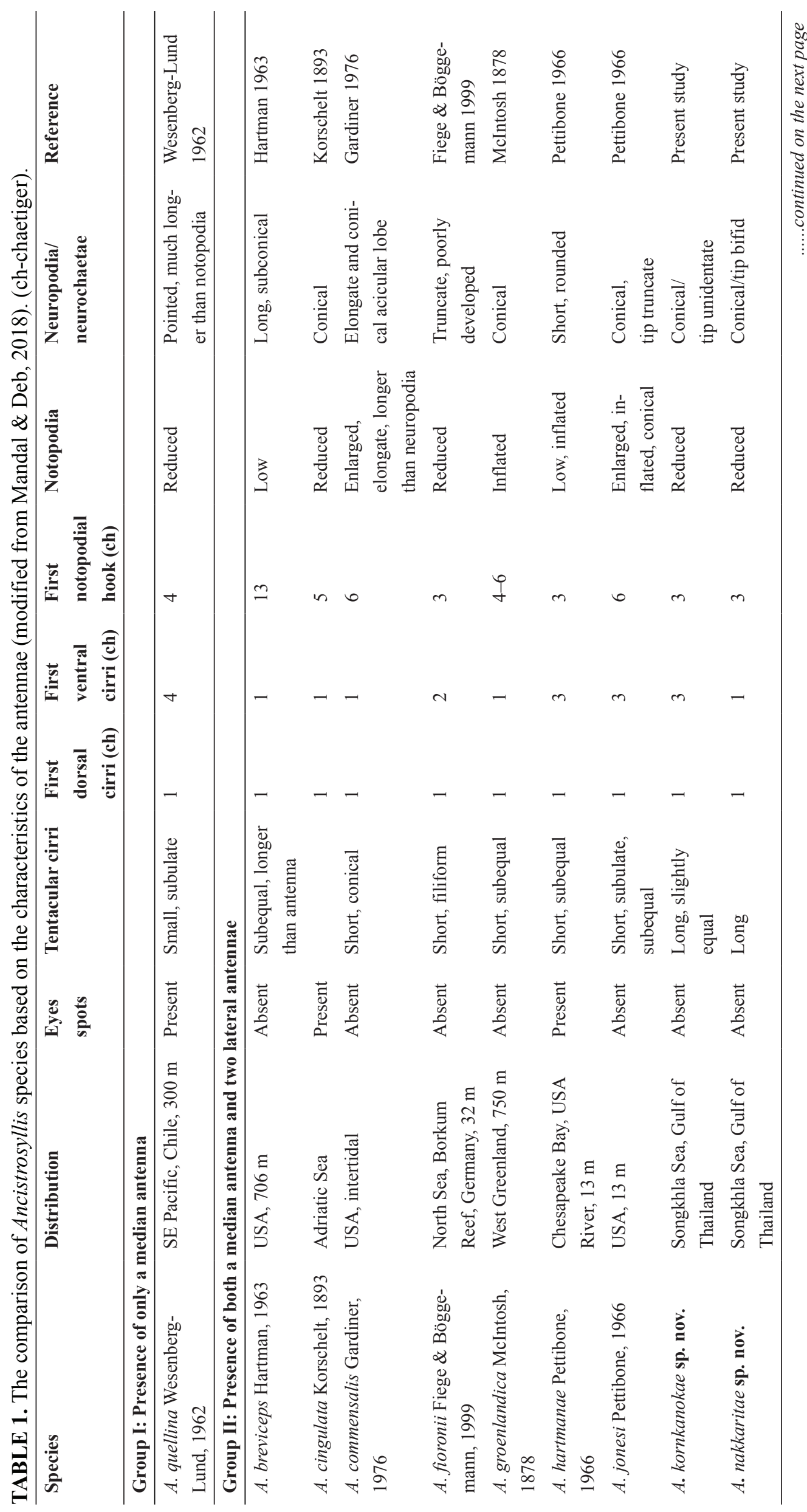

PILARGIDAE FROM THE GULF OF THAILAND 


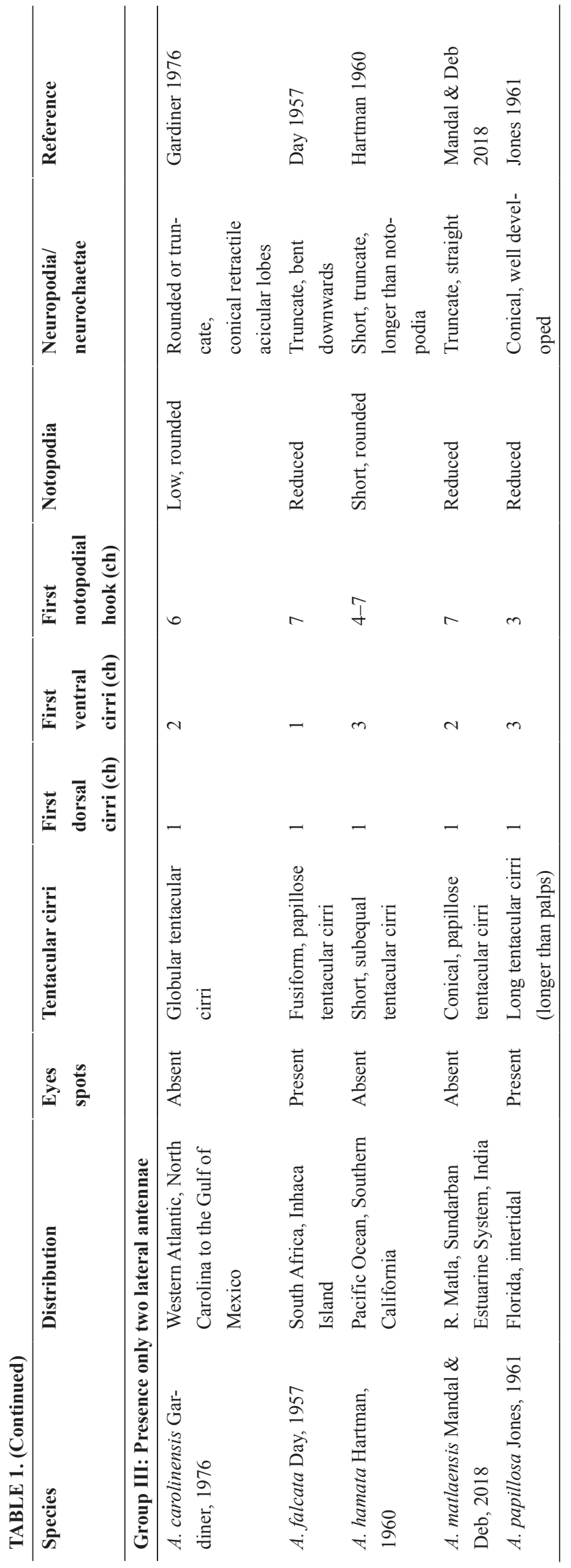


number of neurochaetae per fascicle than $A$. fioronii with up to 12 chaetae per bundle while $A$. fioronii has only a single type neurochaeta with 4-6 chaetae per bundle (Fiege \& Böggemann 1999). Furthermore, A. nakkaritae sp. nov. also differs from $A$. kornkanokae sp. nov. by all neurochaetae with bifid tips, papillae on the body surface and the parapodia are numerous and longer and larger. The neurochaetae of $A$. kornkanokae sp. nov. are unidentate and the papillae on the body surface are smaller than in $A$. nakkaritae.

\section{Genus Cabira Webster, 1879}

Diagnosis. (after Glasby \& Salazar-Vallejo 2021). Pilargids with body cylindrical, integument with few verrucae, larger and more numerous in anterior and posterior ends. Median antenna absent, lateral antennae papilliform. Palps unfused, biarticulated, palpostyle minute. Paired ventrolateral palpal papillae present. Pharynx lacking terminal papillae; proximally with soft papillae or hardened denticles arranged in rows. Two pairs of tentacular cirri, minute. Deep constriction between the first segment and the first chaetiger. Dorsal and ventral cirri papilliform; the latter from chaetigers 1 or 3. Notochaetae are hooks, from chaetigers 6 to 8. Neurochaetae are a variety of capillaries, limbate or nonlimbate, smooth or finely serrated.

\section{Key to species of Cabira Webster, 1879}

(modified after Mandal, Harkantra \& Salazar-Vallejo 2007)

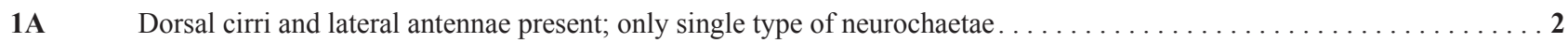

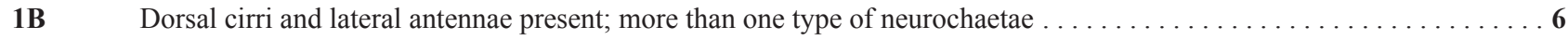

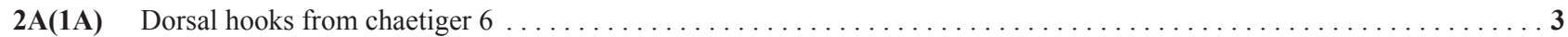

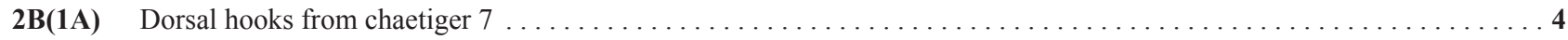

3A(2A) Absence of ventral lateral palpal papillae in the distal part of palpophore... . C. bohajensis Britaev \& Saphronova, 1981; Pacific Ocean, Sea of Japan

3B(2A) Presence of ventral lateral palpal papillae in the distal part of palpophore. . . . . C. pilargiformis Uschakov \& Wu, 1962; China Sea, Pacific Ocean

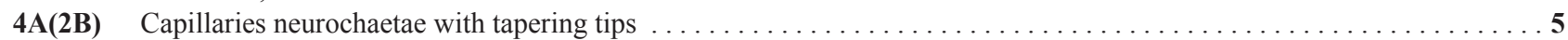

4B(2B) Capillaries neurochaetae with bidentate tips, dorsal cirri from chaetiger 1 ; ventral cirri from chaetiger $3 \ldots \ldots \ldots \ldots$

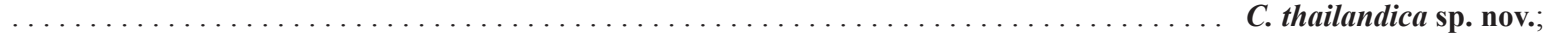
Gulf of Thailand, Western Pacific

5A(4A) Prostomium and peristomium as long as the first $2-3$ chaetigers . . . . . . . $\ldots \ldots \ldots$ incerta Webster, 1879; Chesapeake Bay, Western Atlantic Ocean

5B(4A) Prostomium and peristomium as long as first 4 chaetigers. . . . . . . . . . . . . . . . . . . . . . . . . . $\ldots \ldots \ldots \ldots \ldots \ldots \ldots \ldots \ldots \ldots \ldots \ldots \ldots \ldots \ldots \ldots \ldots \ldots$ rangarajani Mandal, Harkantra \& Salazar-Vallejo, 2007; Arabian Sea, off Goa (India), Indian Ocean

6B(1B) Chaetigers 4-6 with a single short chaeta subdistal enlargement per fascicle dorsal hooks from chaetigers $6-8 \ldots \ldots . .$.

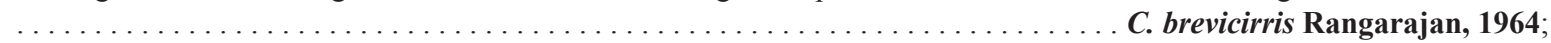
Indian Ocean, South India, Palk Bay

6C(1B) Chaetiger 2 to 17-21 with 1-2 subdistal enlargement, strongly recurved tips chaetae and 1-2 short chaetae with curved tips; and notopodial hooks from chaetiger $8 \ldots \ldots \ldots \ldots \ldots \ldots \ldots \ldots \ldots \ldots \ldots \ldots \ldots \ldots \ldots \ldots \ldots \ldots$ saithipae spov; Gulf of Thailand, Western Pacific

\section{Cabira saithipae sp. nov.}

Figs 9-12

Material examined. Eight specimens, collected from Songkhla Sea, the Gulf of Thailand, Western Pacific. Coll. MEM (Marine Ecosearch Management Co., Ltd.), mud mixed with sand and shells. Holotype: PSUZC-POL-0338 (1 spec.), S09-5 (7³2’01’N, 10042’30”E), 17 Aug 2018, 24.0 m. Paratypes: PSUZC-POL-0339 (1 spec.), S14 (7²6'14”N, 100³6'13”'E), 5 Mar 2014, 15.5 m; PSUZC-POL-0340 (1 spec.), S18-1 (7²1'38’'N, 100³7’01'E), 3 Jun 2015, 16.0 m; PSUZC-POL-0341(1 spec.), S18-2 (7²1’34”N, 100³7’06”E), 3 Jun 2015, 16 m; PSUZC-POL0342 (1 spec.), S09-3 (7³2’01’N, 10042’42”E), 2 Mar 2016, 24.0 m; PSUZC-POL-0343 (2 specs., 1 on SEM stub), S08 (7²9'10’N, 10047’06”E), 18 May 2016, 25.0 m; PSUZC-POL-0344 (1 spec.), S09-1 (7³2’13”N, $100^{\circ} 42$ '42”E), 17 Aug 2018, $24.0 \mathrm{~m}$. 


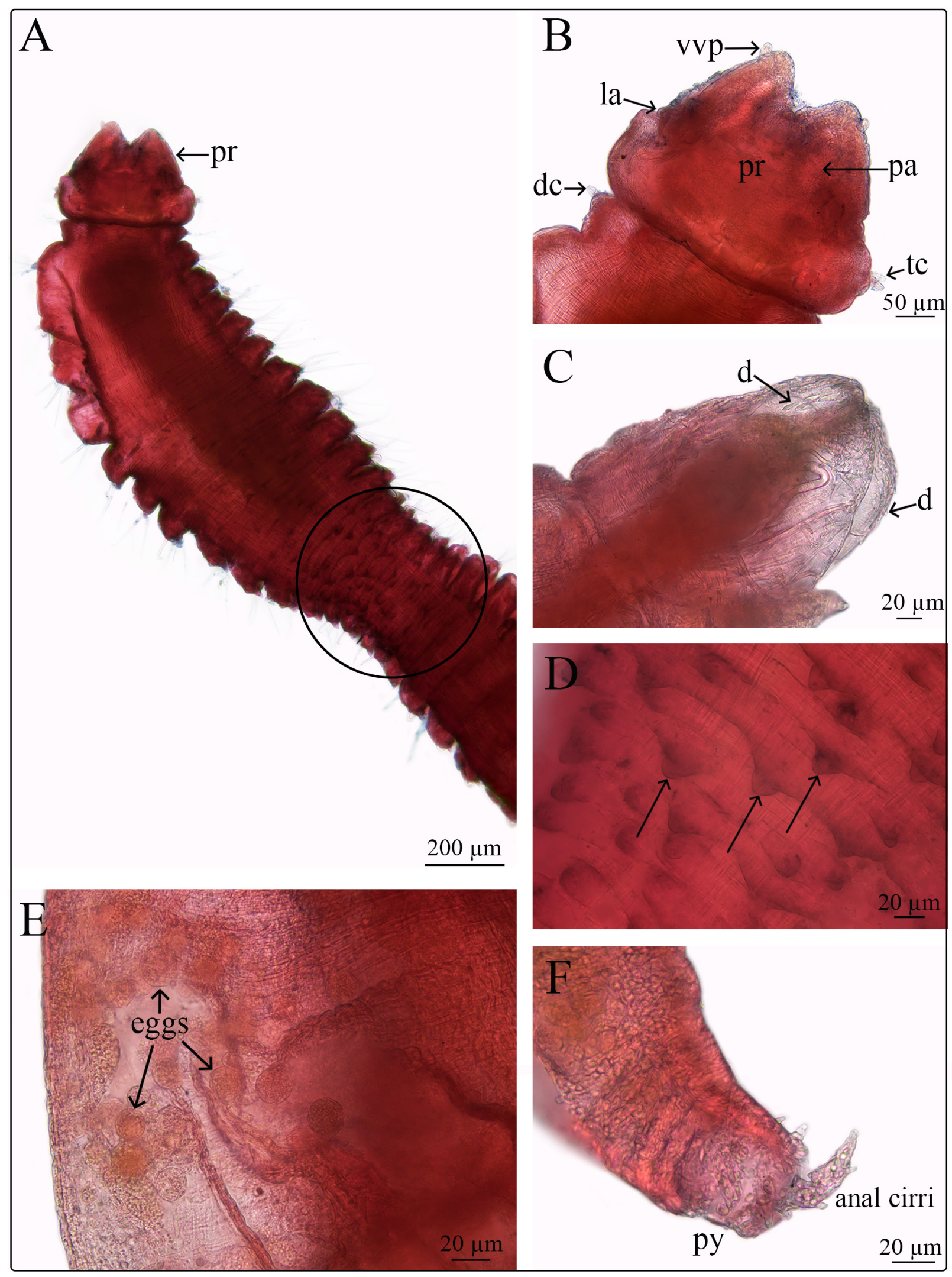

FIGURE 9. Light photographs of Cabira saithipae sp. nov. stained with Shirlastain-A (A, B, D, E, PSUZC-POL-0338 holotype; C, PSUZC-POL-0338; F, PSUZC-POL-0341) A. Anterior region, dorsal view in circle shows large conical papillae; B. Close up prostomium, dorsal view; C. Pharynx, ventral view; D. Close up large conical papillae, dorsal view; E. Eggs in parapodia region, dorsal view; F. Pygidium lateral view. Abbreviations: d: denticle, dc: dorsal cirri, la: lateral antennae, pa: palp, pr: prostomium, py: pygidium, tc: tentacular cirri, vpp: ventrolateral palpal papilla. 
Type locality. Songkhla Sea, Gulf of Thailand (Fig. 1C).

Diagnosis. Cabira saithipae sp. nov. is characterized by the presence of minute papilliform lateral antennae and tentacular cirri, the lack of a median antenna, and dorsal and ventral cirri beginning on chaetiger 1 . Notopodial hooks occur from chaetiger 8 . Three types of neurochaetae in the anterior parapodia: long, slender, non-limbate chaeta, short, broad chaeta with strongly recurved tips, and short, broad chaeta with curved tips.

Description. Holotype largest specimen, incomplete, $11.1 \mathrm{~mm}$ long and $0.46 \mathrm{~mm}$ wide, for about 64 chaetigers. One paratype complete with one anal cirri (other anal cirri broken), about 50 chaetigers, $7.2 \mathrm{~mm}$ long and $0.3 \mathrm{~mm}$ wide. Other paratypes incomplete, 15-38 chaetigers, $1.8-6.6 \mathrm{~mm}$ long, $0.2-0.4 \mathrm{~mm}$ wide. Body whitish, papillose and annulated. Holotype, present large conical papillae at dorsal and ventral of chaetigers 7-17 (Fig. 9A, D).
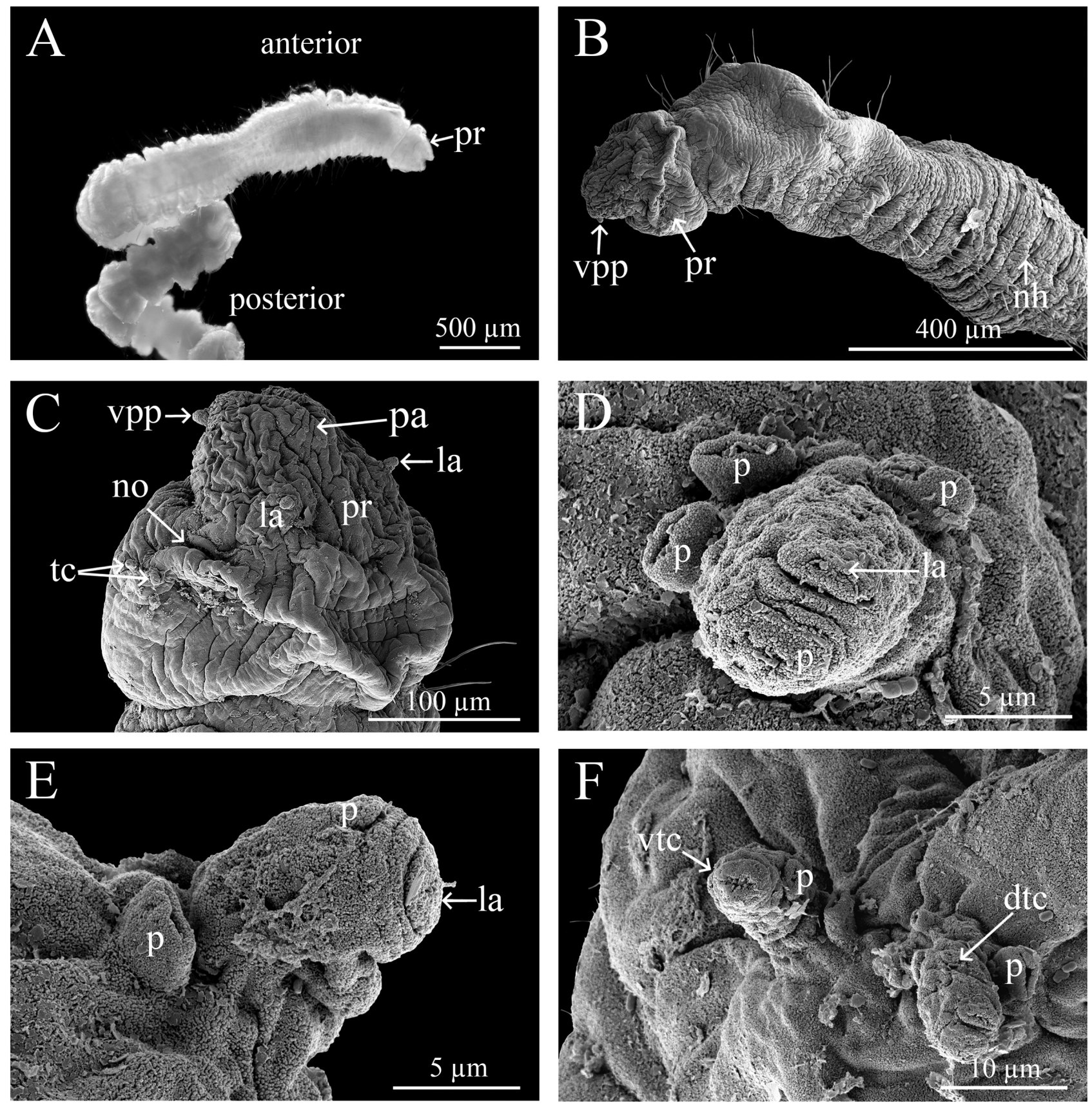

FIGURE 10. Light photograph and scanning electron micrographs of Cabira saithipae sp. nov. (A, PSUZC-POL-0338 holotype; B-F, PSUZC-POL-0343) show A. Light photo, color in alcohol, lateral view; B. Anterior region, lateral view; C. Prostomium, lateral view; D. Lateral antenna, left side, frontal view; E. Lateral antennae, right side, lateral view; F. Tentacular cirri, left side, lateral view. Abbreviations: dtc: dorsal tentacular cirri, la: lateral antenna, nh: notopodial hook, no: nuchal organ, p: papillae, pa: palp, pr: prostomium, tc: tentacular cirri, vtc: ventral tentacular cirri, vpp: ventrolateral palpal papilla. 
Prostomium bilobed, short, broad, wider than long. Median antenna and eyespots absent; palps small, paired minute ventrolateral palpal papillae. One pair of small, short, button-like lateral antennae, basally papillose (Figs 9A-B, 10A-C, 12A). Pair of nuchal organs on the posterolateral margin of the prostomium (Fig. 10C).

Peristomium fused with prostomium, two pairs of small basally papillose, conical, tentacular cirri inserted laterally (Figs 10A-C, 12A). Proboscis not everted in holotype, everted in smallest paratype with rows of denticles (Fig. 9C).

Dorsal tentacular cirri slightly longer than ventral cirri (Fig. 10E-F). Dorsal and ventral cirri are small, papilliform, from first chaetiger.
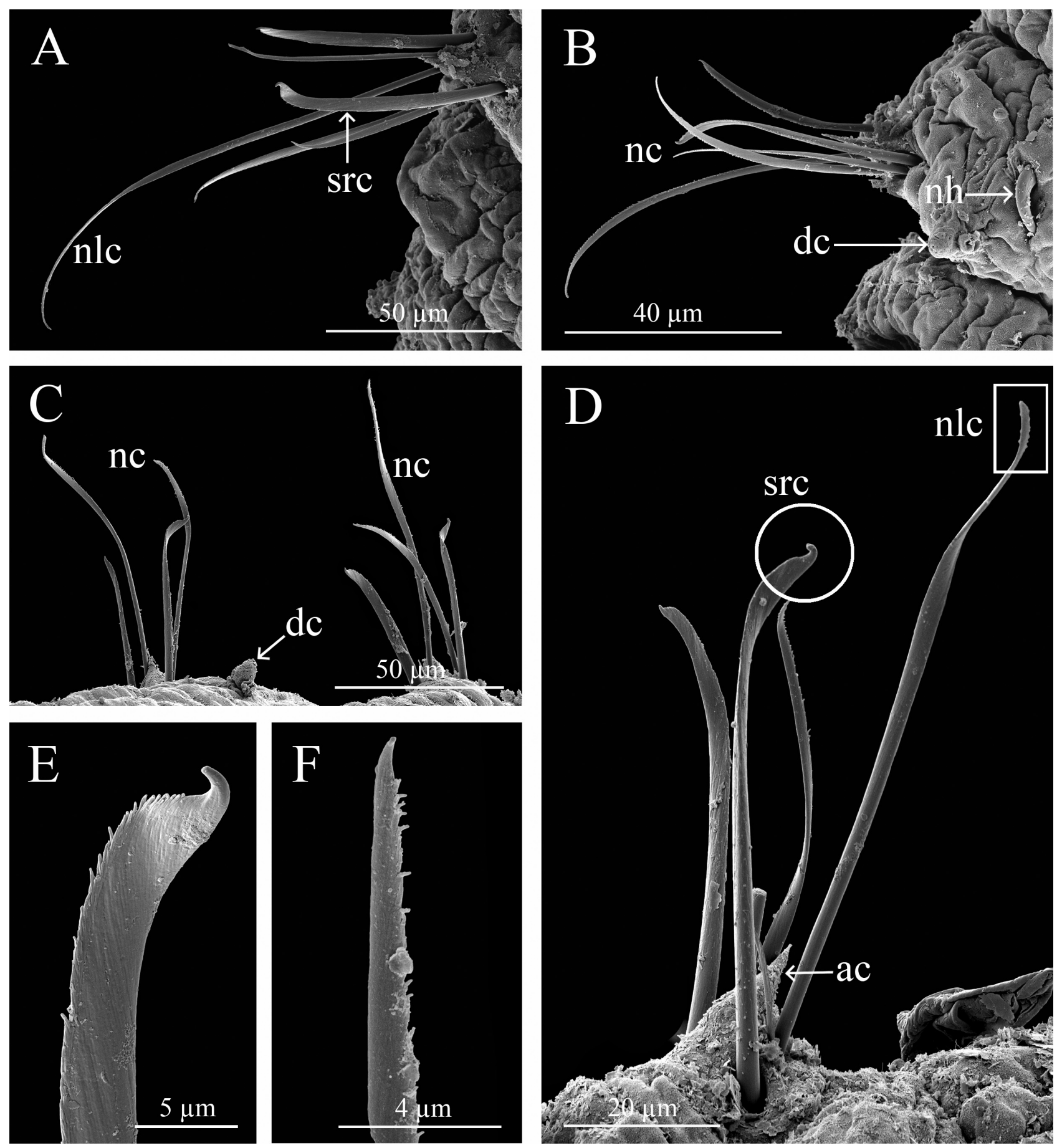

FIGURE 11. Scanning electron micrographs of Cabira saithipae sp. nov. (PSUZC-POL-0343) show A-D. Anterior parapodia and neurochaetae, D. Show short recurved tip chaeta (in circle) and non-limbate chaeta (in the box), lateral view; E. Close up short recurved tip chaeta, lateral view; F. Tip of non-limbate capillary chaeta with subdistally foliose, finely denticulate, tip falcate, lateral view. Abbreviations: ac: acicular chaeta, dc: dorsal cirri, nc: neurochaetae, nh: notopodial hook, nlc: non-limbate capillary chaeta, src: short recurved tip chaeta. 
Parapodia sub-biramous, reduced; notopodial lobes reduced with small dorsal cirrus similar in size throughout. Notopodia with single acicula and 1-2 notopodial hooks. First notopodial hooks start at chaetiger 8 in all specimens; hooks small with strongly curved tip (Figs 11B, 12A). Neuropodia reduced, very short with acicular lobe. Anterior chaetigers from chaetiger 2-17 (chaetiger 2-21 in one paratype) with three types of neurochaetae: 1) long, slender, non-limbate chaeta with subdistally foliose, finely denticulate, tip falcate, 2) short chaeta with strong recurved tip and 3) short chaeta with curved tips; about 4-6 chaetae per fascicle; 3 at upper acicular lobe and 3 at the lower acicular lobe. Each parapodia with 1-2 short strong recurved chaetae, 1-3 short slightly recurved chaetae, and 2-3 long, slender, non-limbate chaetae (Figs 11A-F, 12B-C). Two types of neurochaetae from chaetiger 18-26 or 27, lacking the short broad chaeta with strongly recurved tip, each with four chaetae per fascicle; one short, narrow chaeta with curved tips and 3 non-limbate capillary chaetae; from chaetiger 28 to posterior parapodia, neuropodia with three capillary chaetae; one long chaeta, longer about twice the length of short ones and two short chaetae, length almosty equal.

Pygidium with two anal cirri (0.05 mm long).

Reproduction. Holotype and paratype were collected in August 2018, body with eggs (Fig. 9E).

Etymology. The new species name is honor to Miss Kanoknapat (Saithip) Plathong, older sister of Sakananauthor.

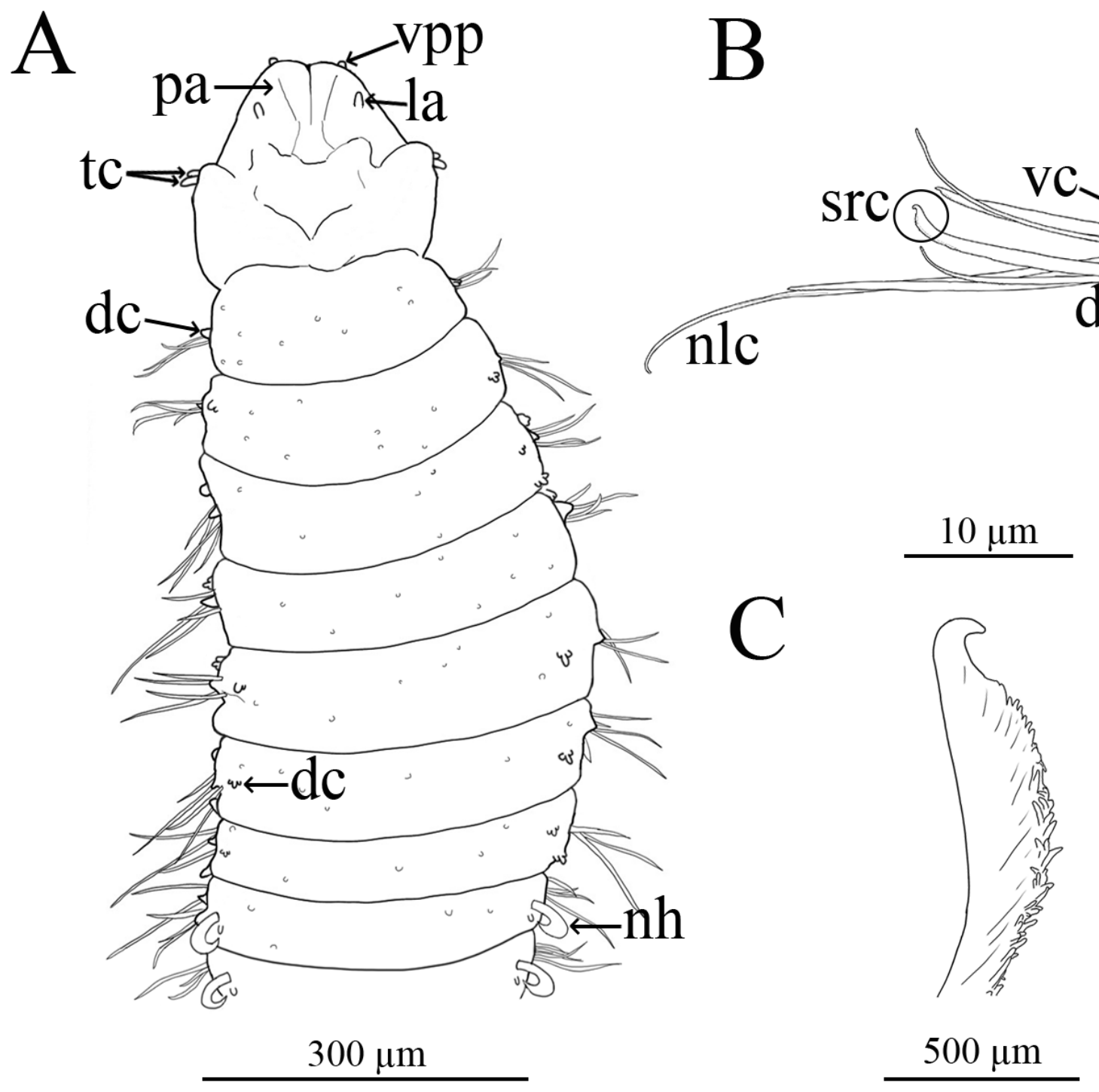

FIGURE 12. Line drawings of Cabira saithipae sp. nov. illustrate A. Anterior region, dorsal view; B. Parapodia, in circle is short broad recurved tip chaeta, lateral view; C. Close up short recurved tip chaeta. Abbreviations: dc: dorsal cirri, la: lateral antenna, nh: notopodial hook, nlc: non-limbate capillary chaeta, pa: palp, src: short recurved tip chaeta, tc: tentacular cirri, vc: ventral cirri, vpp: ventrolateral palpal papilla. 
Habitat. Found at 16-25 m depth, in mud mixed with sand and shells.

Distribution. Only known from type locality - Songkhla Sea, Gulf of Thailand.

Remarks. Cabira saithipae sp. nov. belongs to the second group (Group II) of Cabira species which have more than one type of chaetae (Table 2). It mostly resembles C. brevicirris Rangarajan, 1964 from Palk Bay, Southern India which also has long non-limbate chaetae, short chaetae with strong recurved tips, and short chaetae with curved tips. However, C. saithipae sp. nov. differs from C. brevicirris by having all three types of neurochaetae in antererior chaetigers from chaetiger 2 to 17-21, while $C$. brevicirris has only two types of neurochaetae beginning at chaetigers 4-13 (Rangarajan 1964; Mandal et al. 2007). In addition, Cabira saithipae sp. nov. has large conical papillae on the posterior edge of the annulations from chaetigers $7-17$ both dorsally and ventrally. These conical papillae are absent in C. brevicirris which has mainly square papillae. Moreover, the appearance of the first ventral cirri and the first notopodial hooks in C. saithipae sp. nov. occurs at chaetiger 1 and chaetiger 8, respectively while the first ventral cirri of $C$. brevicirris, begin at chaetiger 1 or 3 and the first notopodial hooks occurs at chaetiger 6-8 (Rangarajan 1964).

Cabira saithipae sp. nov. also differs from $C$. thailandica sp. nov. in that there are three types of neurochaetae and bidentate tipped chaetae are lacking while $C$. thailandica sp. nov. has only a single type of neurochaetae with bidentate tips. Additionally, the first ventral cirri and first notopodial hooks begin at chaetiger 1 and 8 , respectively in C. saithipae sp. nov. while they begin at chaetiger 3 and 7 in C. thailandica sp. nov. (Table 2).

\section{Cabira thailandica sp. nov.}

Figs 13-15

Material examined. 76 specimens, collected from the Songkhla Sea, Gulf of Thailand, Western Pacific. Coll. MEM (Marine Ecosearch Management Co., Ltd.) mud mixed with sand and shells. Details of geographic positions and environmental characteristics of sampling stations are in Table 2. Holotype: PSUZC-POL-0200 (1 spec.), S52 (742’05”N, 10040'15”E), 11 Feb 2015, 23.0 m. Paratypes: PSUZC-POL-0201 (1 spec.), S09-10 (7³1'56”N, 10042'47’'E), 3 Jul 2014, 24.3 m; PSUZC-POL-0202 (1 spec.), S09-6 (7³2’13”N, 10042’21”'E), 20 Feb 2015,

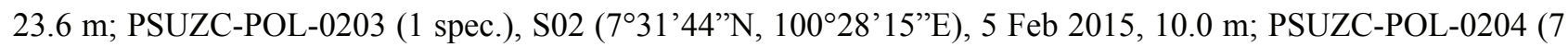
specs., 4 specs. on SEM stubs), S03 (7²1'02”N, 100³1'45”'E), 2 Dec 2015, 9.0 m; PSUZC-POL-0205 (1 spec.), S46 (740'58'N, 100²9’39”E), 22 Feb 2015, 14.5 m; PSUZC-POL-0206 (1 spec.), S19 (7²1'01'”N, 100³6'54”E), 17 Jul 2015, 14.0 m; PSUZC-POL-0207 (1 spec.), S08 (7²9’10”N, 10047’06”'E), 16 Mar 2016, 25.0 m; PSUZCPOL-0208 (1 spec.), S14 (7²6’14”N, 100³6’13”E), 20 Sep 2017, 15.5 m; PSUZC-POL-0209 (1 spec.), S11-2 (7³1'01”N, 100³6’39”E), 27 Mar 2017, 18.9 m; PSUZC-POL-0210 (1 spec.), S11-9 (7³1'11”N, 100³6'18”E), 27 Mar 2017, 18.7 m; PSUZC-POL-0211 (1 spec.), S10-8 (7²8’44”N, 100³6’11”'E), 5 May 2018, 18.5 m; PSUZC-POL-0212 (1 spec.), S09-3 (7³2’01'NN, 10042’41”E), 16 Aug 2018, 24.0 m; AM W.52912 (1 spec.), S05

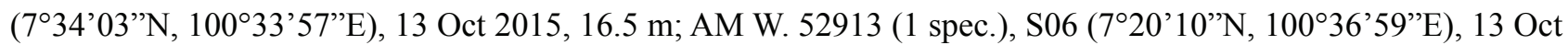
$2015,15.5 \mathrm{~m}$.

Additional Material. S02 (7³1’44”N, 100²8’15”E), 6 May 2014 (3 specs.), 21 May 2015 (1 spec.), 10 m; S03 (7²1'02”N, 100³1’45”E), 6 May 2014 (1 spec.), 2 Dec 2015 (6 specs.), 13 Oct 2015 (1 spec.), 9.0

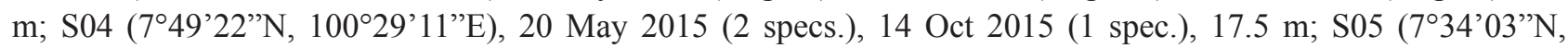
100³3'57’'E), 6 May 2014 (4 specs.), 21 May 2015 (5 specs.), 13 Oct 2015 (3 specs.), 2 Dec 2015 (2 specs.), 15

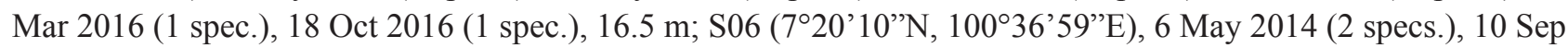
2014 (1 spec.), 2 Dec 2015 (1 spec.), 15 May 2016 (1 spec.), 17 May 2016 (1 spec.), 15.5 m; S07 (744’01”N, 10043’02”E), 6 May 2014 (1 spec.), 26 Jan 2015 (2 specs.), 14 Oct 2015 (3 specs.), 18 May 2016 (2 specs.), 26.5

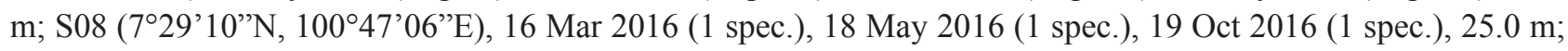
S09-3 (7³2’01”N, 10042’41”E), 2 Mar 2016 (1 spec.), 24.0 m; S09-7 (7³2’19”N, 10042’24”E), 1 Mar 2016 (1 spec.), 23.7 m; S10-4 (7²8'14”N, 100³6’39”'E), 15 Feb 2015 (1 spec.), 19.0 m; S14 (7²6’13”N, 100³6'12”'E), 20 Feb 2015 (3 specs.), 15.5 m; S17 (7³6’16”N, 100³4'48”E), 7 Oct 2015 (2 specs.), 18.0 m; S18-1 (7²1'38”N, 100³7’01'”E), 3 Jun 2015 (4 specs.), 16.0 m; S18-2 (7²1'34”N, 100³7’06”E), 3 Jun 2015 (2 specs.), 16.0 m; S19

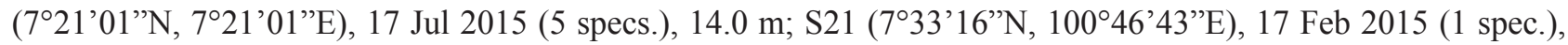
24.0 m; S23 (749’20”N, 100³3’17’'E), 14 Jul 2015 (3 specs.), 20.5 m; S25 (7¹6’28’N, 10048’46”E), 13 Jul 2015 (1 spec.), 6 Oct 2015 (1 spec.), 22.0 m; S38 (7³7’29”N, 10042’53”E), 3 Jun 2015 (3 specs.), 22.0 m; S40 

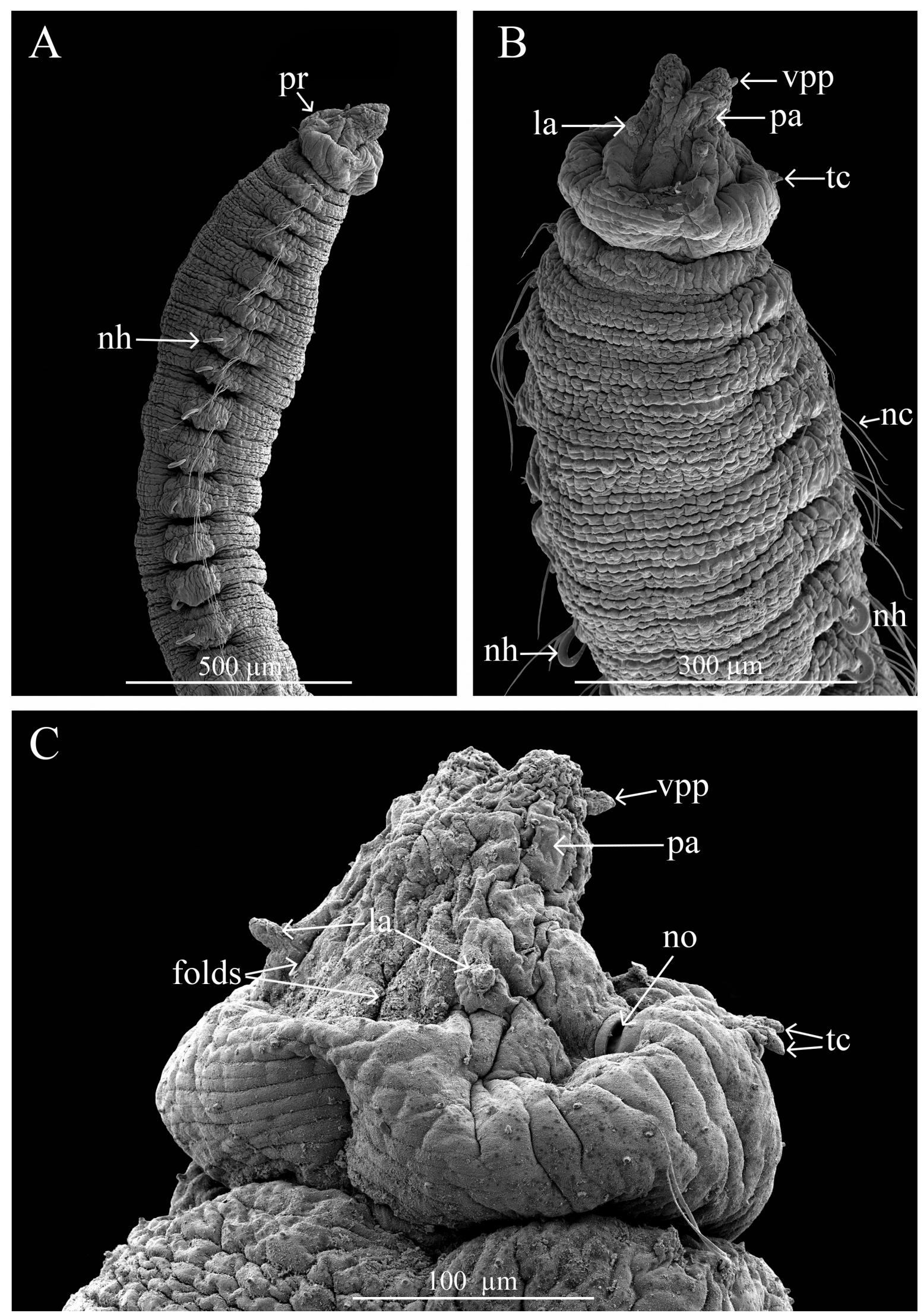

FIGURE 13. Scanning electron micrographs of Cabira thailandica sp. nov. (PSUZC-POL-0204) show A. Anterior region, lateral view; B. Same, dorsal view; C. Prostomium, lateral terior chaetiger with notopodial hook, dorsal view; C. Anterior parapodia, lateral view; D. Neurochaetae, show bidentate tip (in circle), lateral view; E. Close up bidentate tip, lateral view. Abbreviations: dc: dorsal cirri, nc: neurochaetae, nh: notopodial hook, nlc: non-limbate capillary chaeta, vc: ventral cirri vpp: ventrolateral palpal papilla. 


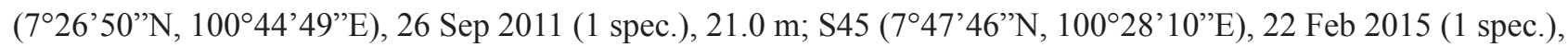

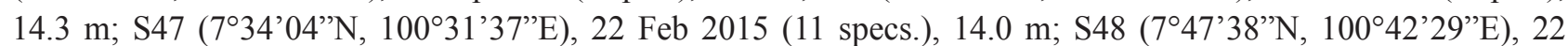
Feb 2015 (1 spec.), 24.6 m; S50 (7³5’01”N, 10046’58”E), 21 Feb 2015 (2 specs.), 22.5 m; S53 (7²7’59”N, 100³1'47’E), 23 Feb 2015 (1 spec.), $14.3 \mathrm{~m}$.

Type locality. Songkhla Sea, Gulf of Thailand (Fig. 1D).
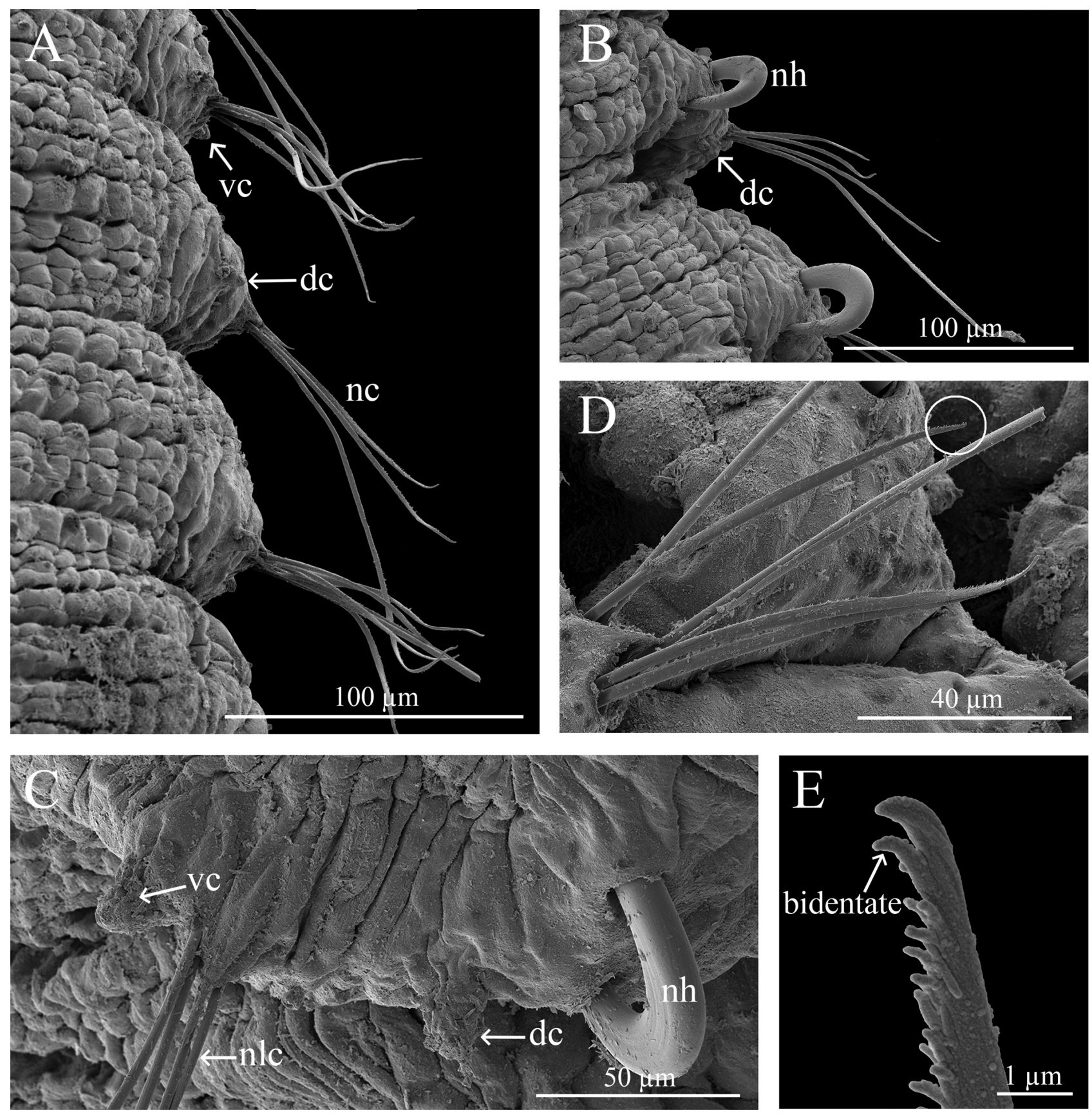

FIGURE 14. Scanning electron micrographs of Ancistrosyllis thailandica sp. nov. (PSUZC-POL-0204) show A. Anterior chaetiger without notopodial hook, left side, lateral view; B. Anterior chaetiger with notopodial hook, dorsal view; C. Anterior parapodia, lateral view; D. Neurochaetae, show bidentate tip (in circle), lateral view; E. Close up bidentate tip, lateral view. Abbreviations: dc: dorsal cirri, nc: neurochaetae, nh: notopodial hook, nlc: non-limbate capillary chaeta, vc: ventral cirri.

Diagnosis. Cabira thailandica sp. nov. is characterized by the presence of minute papilliform lateral antennae and tentacular cirri; median antenna absent; dorsal cirri begin on chaetiger 1 and ventral cirri from chaetiger 3 . Notopodial hooks occur from chaetiger 7. Single type of neurochaetae, long, slender, non-limbate capillary chaeta with bidentate tips.

Description. A small species, holotype complete, $14.4 \mathrm{~mm}$ long and $0.3 \mathrm{~mm}$ wide for 53 chaetigers. Body 
papillose, whitish, transparent with brown and light tan eggs visible in the body cavity, widest anteriorly. Paratypes, one complete about 48 chaetigers (13.8 $\mathrm{mm}$ long, $0.9 \mathrm{~mm}$ wide), one with the last six chaetigers regenerating (350 $\mu \mathrm{m}$ long, $126 \mu \mathrm{m}$ wide), no hooks present in the regenerating region but with two small digitate anal cirri about 57 $\mu \mathrm{m}$ long (others incomplete, $1.6-21.1 \mathrm{~mm}$ long, $0.37-0.74 \mathrm{~mm}$ wide with 14-80 segments).

Prostomium bilobed, short, broad, wider than long (163 $\mu \mathrm{m}$ length and $355 \mu \mathrm{m}$ wide); median antenna and eyespots absent. One pair of lateral antennae; short, small, conical and papillose. Palps posterior on prostomium with longitudinal folds. Pair of nuchal organs on the posterolateral margin of the prostomium (Fig. 13C). Peristomium fuse with prostomium, two pairs of short, conical, papillose tentacular cirri insert laterally (Fig. 11A-C). Dorsal tentacular cirri slightly shorter than ventral cirri.

Parapodia sub-biramous; notopodia reduced, each with very short papillated dorsal cirri, single acicular, and strongly curved notopodial hooks start from chaetiger 7 (Figs 13A-B, 14B, 15A-B). Dorsal cirri present from first chaetiger, continue throughout body. Ventral cirri present from chaetiger 3 (Fig. 13A). Neuropodia short, reduced, all long narrow, non-limbate capillary chaetae with bidentate tips, vary in length, up to six chaetae per fascicle (Figs 14A, B, D, E, 15C).

Pygidium with two long, digitate and papillose anal cirri.

Etymology. The new species is named after Thailand, the country where the specimens were collected.

A

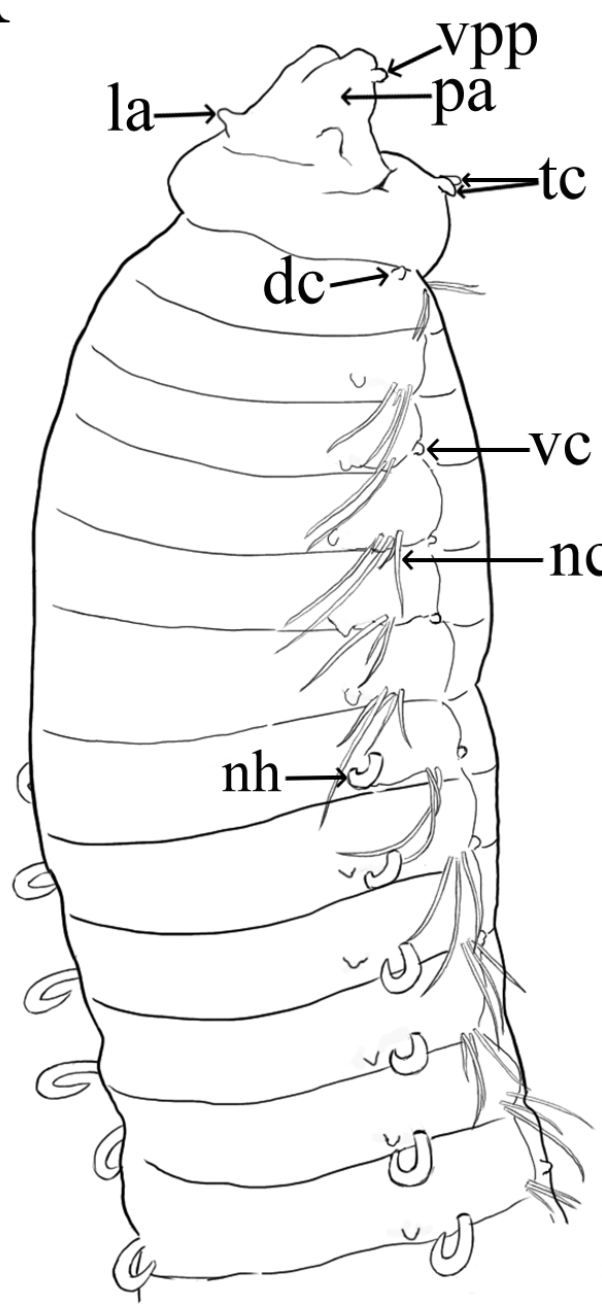

$500 \mu \mathrm{m}$
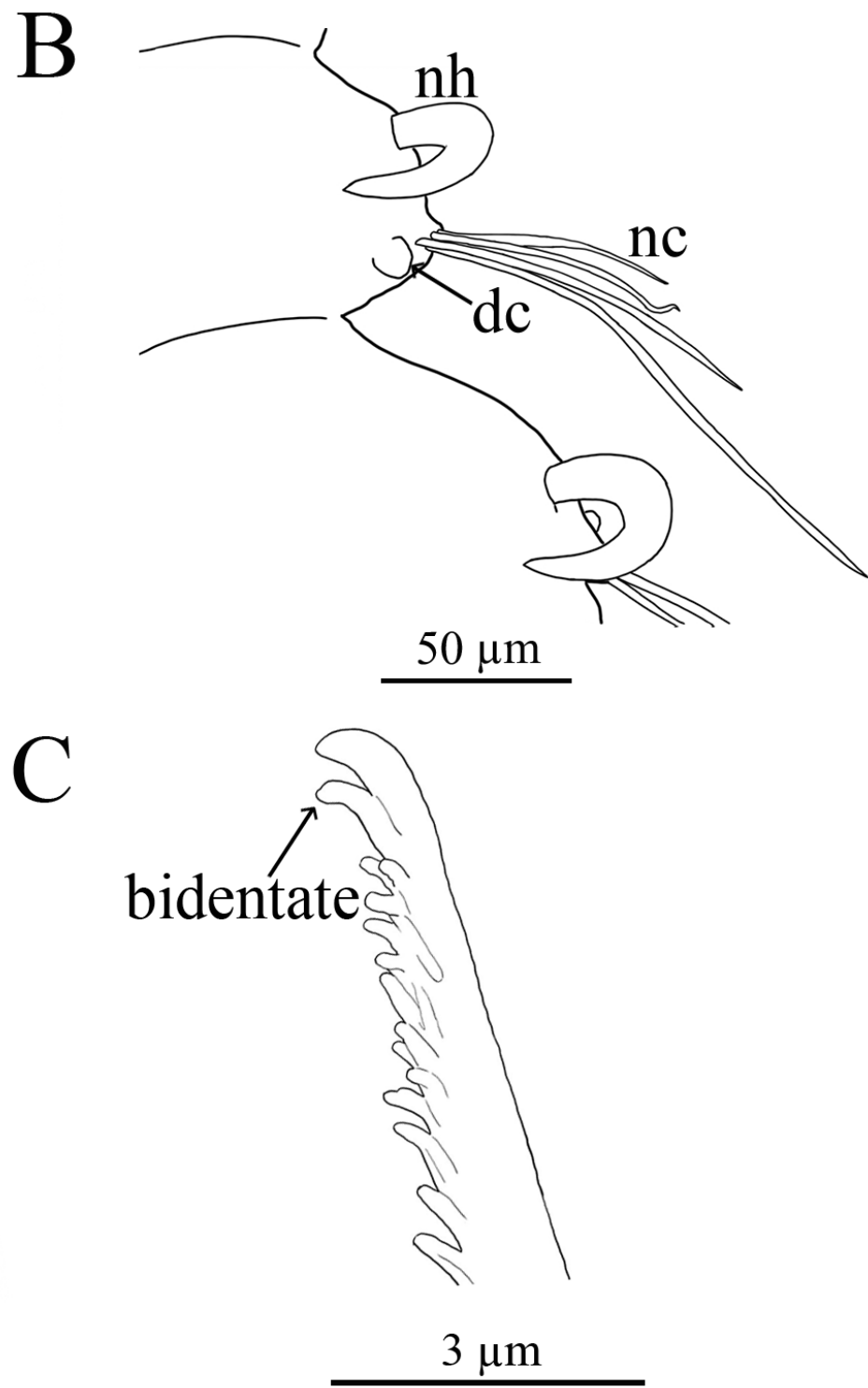

FIGURE 15. Line drawings of Cabira thailandica sp. nov. illustrate A. Anterior end, lateral view; B. Anterior parapodia, ventral view; C. Close up tip of neurochaeta. Abbreviations: dc: dorsal cirri, la: lateral antenna, nc: neurochaetae, nh: notopodial hook, pa: palp, vc: ventral cirri, tc: tentacular cirri, vpp: ventrolateral palpal papilla. 


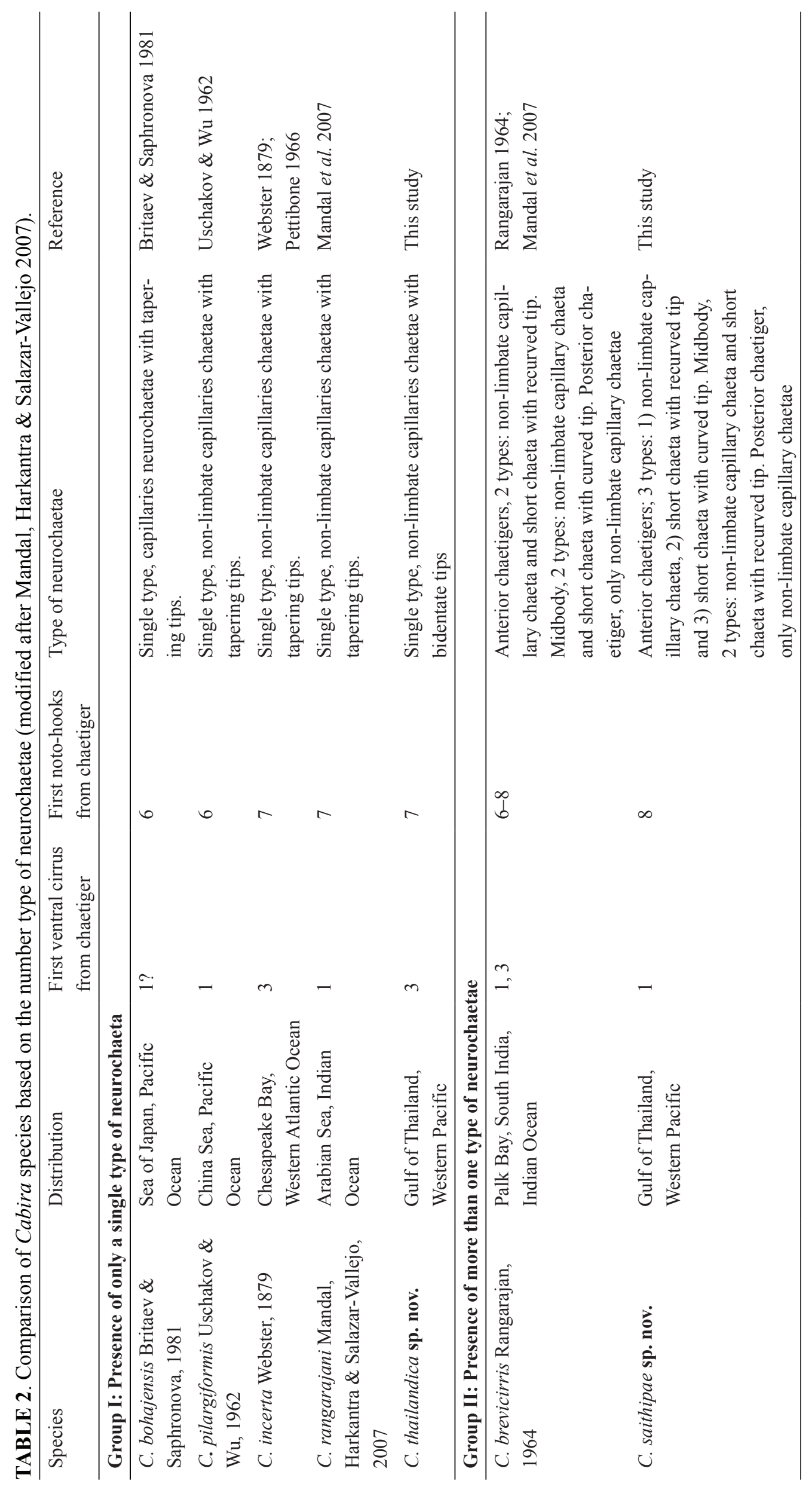


Habitat. Found at 10-27 m depth, in mud mixed with sand and shells.

Distribution. Widely present in the Songkhla Sea, Gulf of Thailand, Western Pacific.

Remarks. Cabira thailandica sp. nov. is characterized by the absence of both eyespots and a median antenna, the presence of two short, papillate lateral antennae, dorsal cirri from the first chaetiger, ventral cirri from chaetiger 3 and notopodial hooks from chaetiger 7. All neurochaetae are narrow, non-limbate chaetae with bidentate tips. It belongs to group I of Cabira species by having only a single type of neurochaetae (Table 2).

Cabira thailandica sp. nov. resembles C. incerta Webster, 1879 from Western Atlantic and C. rangarajani Mandal, Harkantra \& Salazar-Vallejo, 2007 from Indian Ocean (Arabian Sea) in that all three species have a single type of neurochaetae and the first notopodial hooks beginning on chaetiger 7 (Webster 1879; Mandal et al. 2007). However, $C$. thailandica sp. nov. can be distinguished from $C$. incerta and $C$. rangarajani by having bidentate neurochaetae which are lacking in $C$. incerta and $C$. rangarajani.

Cabira thailandica sp. nov. differs from $C$. saithipae sp. nov. by having a single type of long, non-limbate chaeta with bidentate tips, the first ventral cirri occur at chaetiger 3 and first notopodial hooks begin on chaetiger 7. Cabira saithipae sp. nov. has three types of neurochaetae, ventral cirri begin at chaetiger 1 and notopodial hooks start from chaetiger 8.

\section{Acknowledgments}

We would like to thanks Winai Pransuk and all of the MEM (Marine Ecosearch and Management Co., Ltd.) staff for field, laboratory works and editing photographs. Special thanks to CEC International (Thailand Branch) Co., Ltd. for project grants to Sakanan Plathong to study benthic fauna in Songkhla Sea. Thanks to MEM and Marine Science Learning Center, Prince of Songkla University for supported SEM photograph work. Thanks also to Dr. Sumit Mandel for a copy file of Ancistrosyllis matlaensis. We are grateful to Mr. Pacharaphon Plathong and Mr. Monrach Intarasiri for drawing the figures, Mr. Rueangrit Promdam and Dr. Pranee Saardrit, at the PSU Museum for assistant with our collection. Thanks to OSIT, the Office of Scientific Instrument and Testing, PSU for discounted FESEM service and also to Mrs. Apinya Sukolra and Ms. Benjaporn Nooklay for their assistance with SEM.

\section{References}

Britaev, T.A. \& Saphronova, M.A. (1981) New species of the family Pilargidae (Polychaeta) from the Sea of Japan and revision of the genus Cabira. Zoologicheskii zhurnal, 60 (9), 1314-1324.

Day, J.H. (1957) The Polychaete Fauna of South Africa, Part 4, New species and records from Natal and Moçambique. Annals of the Natal Museum, 14 (1), 59-129.

Fauvel, P. (1932) Annelida Polychaeta of the Indian Museum, Calcutta. Memoirs of the Indian Museum, 12 (1), 1-262.

Fiege, D. \& Böggemann, M. (1999) Ancistrosyllis fioronii, a new species of Pilargidae from the North Sea, with a key and synoptic table of characters for all species of the genus Ancistrosyllis McIntosh, 1879 (Annelida, Polychaeta, Pilargidae). Senckenbergiana biologica, 78 (1/2), 135-140.

Gardiner, S.L. (1976) Errant polychaete annelids from North Carolina. Journal of the Elisha Mitchell Scientific Society, 91 (3), $77-220$.

Glasby, C.J. (2000) Family Pilargidae. In: Beesley, P.L., Ross, G.J.B. \& Glasby, C.J. (Eds.), Polychaetes \& Allies: The Southern Synthesis. Fauna of Australia. Vol. 4A, Myzostomida, Pogonophora, Echiura, Sipuncula. CSIRO Publishing, Melbourne, pp. $148-150$.

Glasby, C.J. \& Salazar-Vallejo, S.I. (2021) Pilargidae Saint-Joseph, 1899. In: Purschke, G., Westheide, W. \& Böggemann, M. (Eds.), Handbook of Zoology. Annelida. Pleistoannelida, Errantia II, Phyllodocida. De Gruyter, Berlin, pp. 304-419.

Hartman, O. (1960) Systematic account of some marine invertebrate animals from the deep basins off southern California. Allan Hancock Pacific Expeditions, 22 (2), 69-216.

Hartman, O. (1963) Submarine canyons of southern California. Part III. Systematics: Polychaetes. Allan Hancock Pacific Expeditions, 27 (3), 1-93.

Jones, M.L. (1961) Two new polychaetes of the families Pilargidae and Capitellidae from the Gulf of Mexico. American Museum Novitates, 2049, 1-18.

Korschelt, E. (1893) Über Ophryotrocha puerilis Clap.-Metschn. und die polytrochen Larven eines anderen Anneliden (Harpochaeta cingulata, nov. gen, nov. spec.). Zeitschrift für wissenschaftliche Zoologie, 57, 224-289.

Licher, F. \& Westheide, W. (1997) Review of the genus Sigambra (Polychaeta: Hesionidae), redescription of S. bassi (Hartman, 1947), and descriptions of two new species from Thailand and China. Steenstrupia, 23, 1-20. 
Mandal, S. \& Deb, S. (2018) Ancistrosyllis matlaensis n. sp. (Polychaeta: Pilargidae) from the Sundarban Estuarine System, India. Zootaxa, 4531 (3), 419-429.

https://doi.org/10.11646/zootaxa.4531.3.6

Mandal, S., Harkantra, S.N. \& Salazar-Vallejo, S.I. (2007) Cabira rangarajani n. sp. (Polychaeta: Pilargidae) from the Goa coast, central west coast of India. Zootaxa, 1446 (1), 21-29. https://doi.org/10.11646/zootaxa.1446.1.2

McIntosh, W.C. (1878) On the Annelida obtained during the Cruise of H.M.S. 'Valorous' to Davis Strait in 1875. Transactions of the Linnean Society of London, Series 2 (Zoology), 1 (7), 499-511. https://doi.org/10.1111/j.1096-3642.1878.tb00663b.x

Pettibone, M.H. (1966) Revision of the Pilargidae (Annelida: Polychaeta), including descriptions of new species, and redescription of the pelagic Podarmus ploa Chamberlain (Polynoidae). Proceedings of the United States National Museum, 118 (3525), 155-207. https://doi.org/10.5479/si.00963801.118-3525.155.

Rangarajan, K. (1964) A new polychaete of the family Pilargidae from Palk Bay, South India. Journal of Marine Biological Association of India, 6 (1), 122-127.

Read, G. \& Fauchald, K. (Eds.) (2021a) World Polychaeta Database. Ancistrosyllis McIntosh, 1878. Accessed through: World Register of Marine Species. Available from: http://www.marinespecies.org/aphia.php?p=taxdetails\&id=129462 (accessed 30 March 2021)

Read, G. \& Fauchald, K. (Eds.) (2021b) World Polychaeta Database. Cabira Webster, 1879. Accessed through: World Register of Marine Species. Available from: http://www.marinespecies.org/aphia.php?p=taxdetails\&id=157289 (accessed 01 September 2021)

Salazar-Vallejo, S.I., Nishi, E. \& Anguspanich, S. (2001) Rediscovery of Talehsapia annandalei (Polychaeta: Pilargidae) in Songkhla Lagoon, Thailand. Pacific Science, 55, 267-273.

Saint-Joseph, A.A. de (1899) Note sur une nouvelle famille d'Annélides Polychètes. Bulletin du Muséum d'Histoire Naturelle, Paris, 5, 41-42.

Uschakov, P.V. \& Wu, B.L. (1962) The Polychaetous annelids of the family Syllidae, Hesionidae, Pilargiidae, Amphinomidae and Eunicidae (Polychaeta, Errantia) from the Yellow Sea. Studia Marina Sinica, 1 (1), 57-85.

Webster, H.E. (1879) The Annelida Chaetopoda of the Virginian coast. Transactions of the Albany Institute, 9, $202-269$.

Wesenberg-Lund, E. (1962) Polychaeta Errantia. In: Reports of the Lund University Chile Expedition 1948-49. 43. Universitets Arsskrift, Avd. 2, 57 (12), 1-137. 